\title{
Recent developments on fabrication of Al-matrix composites reinforced with quasicrystals: From metastable to conventional processing
}

\author{
Witor Wolf 1 ,a) (D), Claudemiro Bolfarini², Claudio S. Kiminami², Walter J. Botta ${ }^{2}$ \\ ${ }^{1}$ Departamento de Engenharia Metalúrgica e de Materiais, Universidade Federal de Minas Gerais, Belo Horizonte, MG 31270-901, Brazil \\ ${ }^{2}$ Departamento de Engenharia de Materiais, Universidade Federal de São Carlos, São Carlos, SP 13565-905, Brazil \\ a) Address all correspondence to this author. e-mail: witorw@gmail.com
}

Received: 25 May 2020; accepted: 25 September 2020; published online: 2 February 2021

Quasicrystalline alloys and their composites have been extensively studied due to their complex atomic structures, mechanical properties, and their unique tribological and thermal behaviors. However, technological applications of these materials have not yet come of age and still require additional developments. In this review, we discuss the recent advances that have been made in the last years toward optimizing fabrication processes and properties of Al-matrix composites reinforced with quasicrystals. We discuss in detail the high-strength rapid-solidified nanoquasicrystalline composites, the challenges involved in their manufacturing processes and their properties. We also bring the latest findings on the fabrication of Al-matrix composites reinforced with quasicrystals by powder metallurgy and by conventional metallurgical processes. We show that substantial developments were made over the last decade and discuss possible future studies that may result from these recent findings.

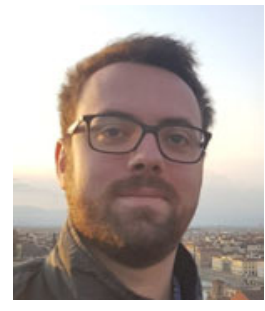

Professor Witor Wolf joined the Federal University of Minas Gerais (UFMG), Brazil, as an adjunct professor in May 2018 after receiving his Ph.D. in the same year, from the Federal University of São Carlos (UFSCar), Brazil, with a period as a visiting researcher at Yale University, USA, in 2017. Witor obtained his B.Eng. and M.S. from UFSCar, all in the field of Materials Science and Engineering. His interest in unconventional metallic materials, their fabrication and characterization began as an undergraduate student, working on extra-curricular research activities that were related to fabrication and characterization of quasicrystalline composites. Since then, most of his research work was focused on applying several fabrication methods and strategies to discover new Al-based quasicrystalline compositions, ranging from metastable to conventional processing such as melt-spinning, gas-atomization, powder metallurgy, thermal spraying, spray-forming, and conventional casting. Witor has also fabricated quasicrystalline alloys using magnetron co-sputtering to apply combinatorial strategies for manufacturing quasicrystalline alloy libraries. His current research activities are focused on the development of wear-resistant Al-matrix composites reinforced with quasicrystals using spray-forming, conventional casting and high-pressure torsion.

\section{Introduction}

Quasicrystals were first reported in 1984 by Shechtman et al. [1]. They were observed in a rapidly solidified Al-Mn alloy, displaying a distinct point group symmetry from all previously known metallic structures, $m \overline{3} \overline{5}$. This point group contains a 5 -fold rotational symmetry, which makes this atomic structure incompatible with translational symmetry. Quasicrystals are known to be formed by nonconventional structural units, such as icosahedral and decagonal, yielding 5-fold and 10 -fold rotational symmetries, respectively, which are found in the vast majority of these phases [2] and can be identified, for example, by electron diffraction analysis, Fig. 1, taken from Bindi et al. [3]. Octagonal and dodecagonal structural units may also be found in specific alloy systems [2]. These units cannot be properly referred to as unit cells since they lack translational symmetry. For instance, icosahedral quasicrystals have an icosahedron as a structural unit, which cannot alone fill a volume without leaving gaps. Thus, in certain atomic sites of this atomic structure, a second "unit cell" would be necessary to completely fill the space. One of the 

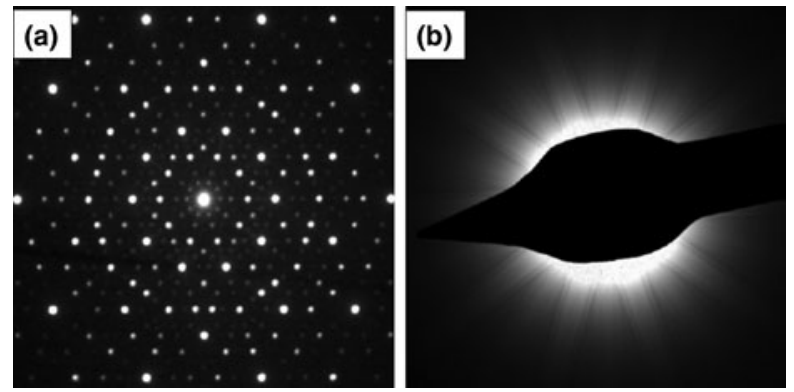

Figure 1: Electron diffraction patterns of a natural decagonal quasicrystal, using (a) selected area and (b) convergent beam electron diffraction pattern. This quasicrystal was found in the Khatyrka meteorite. Adapted from Bindi et al. [3]. The image is licenced under CC BY-ND 4.0 (http://creativecommons.org/licenses/by/4.0/).

models used to understand how this atomic structure can fill the space is the Penrose Model. Following this model, quasicrystals would be formed by two different tiles (unit cells), which must be placed edge to edge with specific matching rules that would allow perfect space filling. These rules lead to a mosaic picture displaying 5 -fold symmetry, which is nonperiodic and ordered at the same time as the quasicrystals [4].

These phases have been extensively studied due to their unique atomic structures and their functional properties, including tribological and thermal behaviors, as well as to their mechanical properties [5]. However, technological applications involving load-bearing components have not yet reached a mature level. This can be attributed to several reasons, two of the most important being (i) their usually complicated processing that either requires rapid solidification or powder metallurgy methods and (ii) their inherent brittleness. This latter issue led to substantial efforts by the academic community to fabricate composites reinforced with these phases to balance the brittleness of the quasicrystals with the presence of a ductile matrix. The present review aims to discuss the studies focused on developing these composite materials over the past decade. This review also brings to the discussion the first published studies that were, mostly, responsible for the advances on quasicrystal-related research reported recently. We will begin with a short review on the general aspects of quasicrystal-forming metallic systems, their properties, and applications, and then, the focus will be on developments of quasicrystal-reinforcing composites for use as wearresistant and high-strength materials.

\section{General Aspects of Quasicrystals and the Motivation for Using Them as Reinforcing Phases in Composites}

\section{Quasicrystal-forming systems}

Most of the metallic quasicrystal-forming systems are Al-based, with hundreds of alloy compositions found to date. Among the most important quasicrystal-forming $\mathrm{Al}$-based systems are $\mathrm{Al}-$ $\mathrm{Mn}$ [1], Al-Cr [6], Al-Fe-Cr [7], Al-Cu-Fe [8], Al-Ni-Co [9, 10], Al-Cu-Co [9], Al-Cu-Fe-Cr [11], Al-Pd-Mn [12], and their modifications through alloy addition $[13,14,15,16]$. Most of these quasicrystals were discovered in the early 1990s by Inoue, Tsai and collaborators. In addition to Al-based systems, other important metallic systems forming quasicrystals are worth mentioning, such as Mg-based [17, 18, 19, 20], Ti-based [21, 22], and Cd-based [23, 24].

Quasicrystals can be divided in relation to their "forming ability" from the metallic melt. While most systems can form quasicrystals only through rapid solidification, there are systems that can form them using conventional metallurgical processes (usually slow solidification processes). Sometimes this division is discussed in the literature regarding the stability of the quasicrystalline phases, considering as stable phases the ones that can be formed in slow solidification conditions, and as metastable phases the ones that require rapid solidification. This classification is, however, not strictly precise since establishing unequivocally the stability of quasicrystals is difficult. These phases usually form from peritectic reactions, grow in a sluggish fashion, and are surrounded by complex phases. This makes the identification of phase boundaries and phase stability very challenging. Additionally, most of the so-called stable quasicrystals are actually not stable in low temperatures such as the icosahedral phase that forms in the $\mathrm{Al}-\mathrm{Cu}-\mathrm{Fe}$ system, which decomposes into a crystalline approximant below a certain temperature [2]. Thus, the term "stable" when referred to quasicrystals should be used with caution. However, we will sometimes make use of it when discussing quasicrystals that were experimentally observed in microstructures even after long annealing thermal treatments. It should be mentioned though, that this fact alone does not suffice to prove the thermodynamic stability of a phase.

Several examples can be found in the literature about Al-based quasicrystals fabricated under low solidification conditions. The most studied one belongs to the $\mathrm{Al}-\mathrm{Cu}-\mathrm{Fe}$ system $[2,25,26,27]$, although a significant amount of papers have been published on Al-Ni-Co [15, 28, 29, 30, 31, 32] and $\mathrm{Al}-\mathrm{Cu}-\mathrm{Fe}-\mathrm{Cr}[5,11,14,33]$ systems. Usually, it is observed that only alloys containing three or more elements can form quasicrystals under these processing conditions. However, Tsai et al. [23] have shown the formation of a stable quasicrystal in a Cd-Yb alloy. These "stable" quasicrystals are of great interest because they can be fabricated on a large scale, by different processing methods. Most quasicrystals, however, can only be fabricated by rapid solidification of metallic melts. These "metastable" quasicrystals are found in several Al-based systems, such as Al-Mn [34], Al-Cr [6], $\mathrm{Al}-\mathrm{V}$ [6], Al-Fe-Cr [7], and in their chemical modifications $[13,35,36,37]$. 

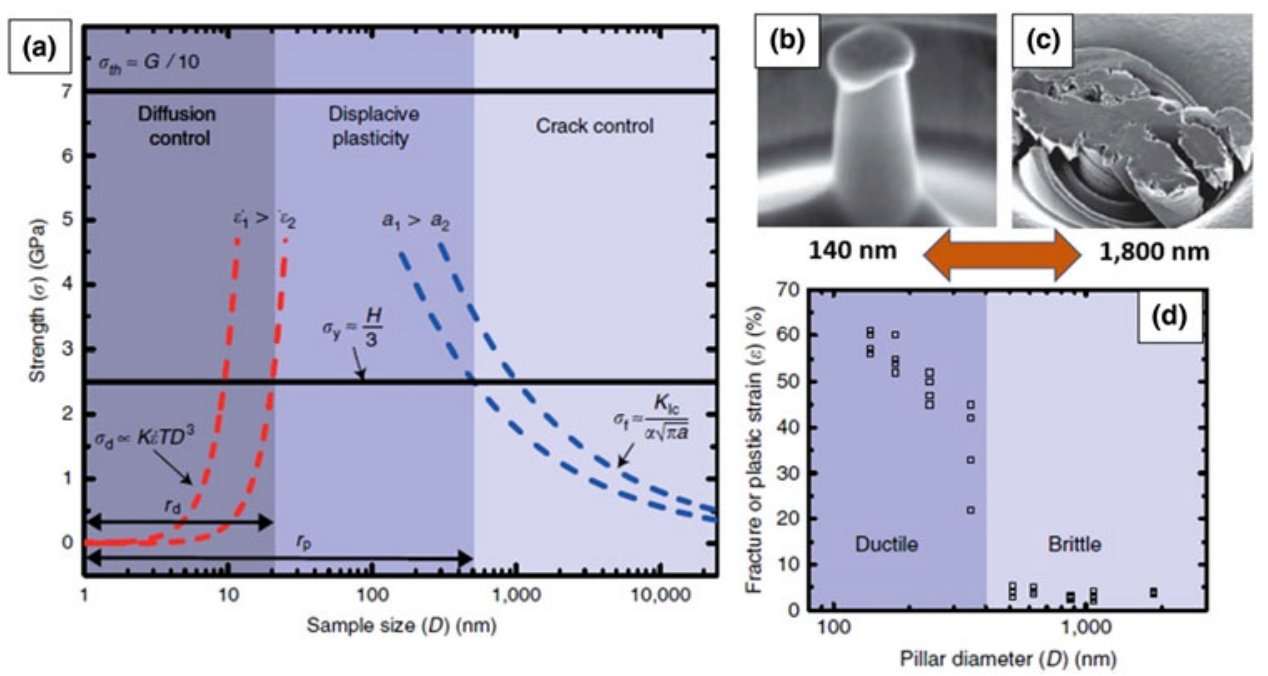

Figure 2: (a) Strength and fracture/deformation mechanisms for icosahedral Al-Pd-Mn pillars. According to Zou et al. [49], the sample size of a single quasicrystal pillar of the system Al-Pd-Mn that would lead a transition from brittle fracture mode (crack control) to a plastic deformation mode (displacive plasticity) is close to $400 \mathrm{~nm}$. Above this size, the sample fracture is dominated by Griffith's criterion. Below that size, the yielding stress (Hardness/3) of the quasicrystal would be lower than its fracture resistance, and thus, the material would experience plastic deformation even at room temperature. If the sample size is further reduced, there will be a substantial increase in the plasticity observed until a certain point from which, it will begin to decrease due to diffusion control of the plastic flow, reducing the strength as the surface-to-volume ratio increases. (b) $140 \mathrm{~nm}$ diameter Al-Pd-Mn quasicrystal pillar after mechanical testing, displaying plastic strain close to $60 \%$. (c) $1800 \mathrm{~nm}$ diameter Al-Pd-Mn quasicrystal pillar after mechanical testing, displaying brittle fracture with limited plastic strain, 3\%. (d) Plastic strains observed in the different sized samples analyzed in that study. Adapted from Zou et al. [49]. The images are licenced under CC BY-ND 4.0 (http://creativecommons.org/licenses/by/4.0/).

\section{Functional properties and technological applications}

Al-based quasicrystals show interesting tribological properties such as high hardness, low friction coefficient, and nonstick properties $[5,38,39]$. Thus, many efforts have been made toward the fabrication of quasicrystalline coatings with improved tribological properties, especially for applications involving sliding wear $[5,40,41,42,43,44]$. However, these materials are not currently applied on a large scale and their production is basically restricted to scientific research up to now. The closest application achievement of quasicrystalline coatings, which even reached mass production, was as nonstick coating on frying pans, aiming to replace Teflon ${ }^{\circledast}$ in kitchen utensils [45]. However, this application was not successful, and the product was discontinued. According to Dubois [45], this was due to the pan manufacturer that did not apply the necessary thermal treatment after the plasma spray process, which was required to enhance the material's corrosion resistance.

Al-based quasicrystals are also heat and electrical insulators and potential applications of these materials as thermal barrier coatings have been proposed and studied. An $\mathrm{Al}-\mathrm{Co}-\mathrm{Fe}-\mathrm{Cr}$ alloy that forms an approximant phase of the quasicrystal has been studied as a potential candidate to be applied as thermal barrier coatings in engines [5, 46]. Quasicrystalline approximants are phases with complex crystalline structures, usually containing several atoms. These structures present many atomic configurations that resemble a quasicrystal structure; however, they are periodic phases. They usually form in neighboring quasicrystalline compositions and the chemical and structural similarities lead to physical properties that resemble the quasicrystals [5, 47]. The interest behind using quasicrystals for heat insulation is due to their thermal expansion coefficient, which is similar to the usual metallic materials used as substrates in these applications, such as steels and superalloys. This similarity in the thermal expansion coefficient can potentially reduce interfacial thermal stresses generated between the traditional thermal barrier coatings (ceramic materials) and metallic substrates.

Despite interesting physical properties presented by quasicrystals, using them in environments where mechanical loads are relatively high becomes restricted due to their inherent brittleness. Quasicrystals are particularly brittle at room temperature due to difficulties of dislocation movement without diffusion and in fact, they only experience plastic deformation in temperatures above $\sim 70 \%$ of its melting temperature [48]. Zou et al. [49] have performed an interesting study on determining a limiting sample size where the mechanical behavior of a single icosahedral Al-Pd-Mn quasicrystal changes from brittle to ductile at room temperature, see Fig. 2. They produced single quasicrystalline pillars using an FIB (focused ion beam) system with cylindrical shapes [Figs. 2(b) and 2 (c)] and diameters ranging from $140 \mathrm{~nm}$ to $2 \mu \mathrm{m}$ and then performed compressive tests using a nanoindenter. They showed that the single quasicrystal can display significant compressive strain [up to $50 \%$, Fig. $2(\mathrm{~d})$ ], at room temperature, when the 
sample size is below $350-510 \mathrm{~nm}$. This is an important result because it shows that only nano-sized quasicrystalline samples can display plastic deformation at room temperature. Thus, using quasicrystals in "large" (above nanometer) components will always be restricted due to their brittleness and they have to be analyzed such as the ceramic materials, where fracture strength can be estimated using Griffith's criterion [50].

The brittle behavior restricts single-phased quasicrystals to be used as protective coatings (in applications involving mechanical stresses) and prohibits them from being used in bulk form. Even wear protection coating applications can be challenging because the quasicrystalline layer usually presents cracking, which is developed upon cooling during coating fabrication. Since cracking introduces large defects inside these materials, according to Griffith's criterion, the final product will have relatively low fracture resistance. This is particularly important for the final wear resistance of the material and restricts the feasibility of obtaining wear-resistant coatings even with deposition processes that can yield high-quality coatings or films. Thus, even if the quasicrystal layer shows a high-quality microstructure, their application is restricted to low load levels during operation or testing. For instance, the wear behavior on pin-on-disk testing of single-phased quasicrystalline coatings is extremely sensitive to the loads applied during the tests, as it also happens for ceramic materials [51]. Single-phased quasicrystalline coatings behave well under low loads during wear testing. However, if sufficiently high loads are applied, the coatings will fail catastrophically and the coating's integrity will be impaired.

As a consequence, for applications involving mechanical stresses, it is of great interest to use the unique quasicrystalline properties as reinforcing phases on metal matrix composites (MMCs). This can be achieved by different methods depending on the quasicrystal system and on the application targeted. For instance, fabricating high-strength $\mathrm{Al}$ alloys reinforced with quasicrystals depends on obtaining nanometric quasicrystalline particles that will provide superior mechanical strength, particularly at high temperatures $[52,53]$. Wear-resistant $\mathrm{Al}$ alloys, on the other hand, usually present coarse hard phases embedded in the $\mathrm{Al}$-matrix, as the Al-Si alloys. Therefore, obtaining coarse quasicrystalline particles showing good metallurgical bond with the Al-matrix is important. Since MMCs are the main scope of the present review, the recent developments on this topic reported in the literature will be discussed in detail in the next sections.

Several applications, other than protective coatings and highstrength alloys, have also been studied for quasicrystals, including their use as: solar light absorbers [45], abrasive polishing agent [54], reinforcing agents in polymers $[55,56]$, catalysts $[57,58$, 59], hydrogen storage $[60,61,62,63]$, among others. We will not discuss them in this review any further. More information regarding these properties and applications can be found in the detailed and high-quality reviews by Dubois [5, 45, 64].

\section{Manufacturing quasicrystals and their composites}

Fabrication of single-phased quasicrystalline alloys can be achieved by several means, ranging from nonconventional to conventional metallurgical methods. They include mechanical alloying [65,66], rapid solidification processes, such as meltspinning [67], gas-atomization [2], and Cu-mold quenching [68], thermal spraying and film deposition [69] and also by conventional casting [2]. Usually, single-phased quasicrystals are obtained from metallic systems that can form these phases under more stable (low cooling rates) processing conditions. This is because normally, these phases form from peritectic reactions, and thus, subsequent thermal treatments are necessary to obtain a single-phased quasicrystalline alloy. For further details on fabrication of single-phased quasicrystals, the reader is urged to refer to a review by Huttunen-Saarivirta [2].

On the other hand, fabricating MMCs reinforced with quasicrystalline phases may be done using virtually any quasicrystal system. The "stable" quasicrystals reinforcing a metallic matrix are mostly fabricated by powder metallurgy. In this case, the quasicrystal is produced either by gas-atomization or mechanical alloying, and then, the composite can be fabricated by different methods that can include: a mechanical mixture of powders to be subsequently consolidated [70], deposited onto a substrate by thermal spraying [40], spray formed [71], conventionally casted [72], and more recently by additive manufacturing [73]. In turn, MMCs reinforced with "metastable" quasicrystals need to be processed using rapid solidification techniques since they only form under these conditions. The most commonly used methods are melt-spinning [13], Cu-mold quenching [74], gas-atomization [75], thermal spraying [76], and additive manufacturing [77].

The next sections will discuss, in detail, developments and advances reported in the literature over the past decade (and some older, but groundbreaking studies as well) that include fabrication and characterization of MMCs reinforced with different quasicrystalline systems. We aim to bring a critical evaluation of what has been done to date and the next challenges to be faced to advance in future applications of these materials. We will begin with metastable processing involving rapid solidification methods and then we will move to the "stable" quasicrystalline-based composites.

\section{Al-Matrix MMCs Reinforced with Nano-Sized} Quasicrystals

\section{MMCs produced by melt-spinning and Cu-mold quenching}

Most of the initial studies about quasicrystal-reinforcing composites were performed by melt-spinning or $\mathrm{Cu}$-mold quenching (usually die-casting) a liquid metal [53, 78, 79, 80, 81, 82]. The reason for using melt-spinning and die-casting is related to 


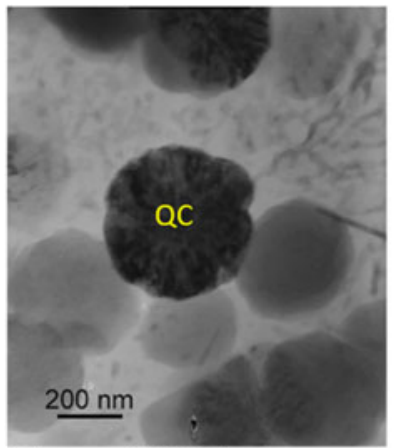

(a)

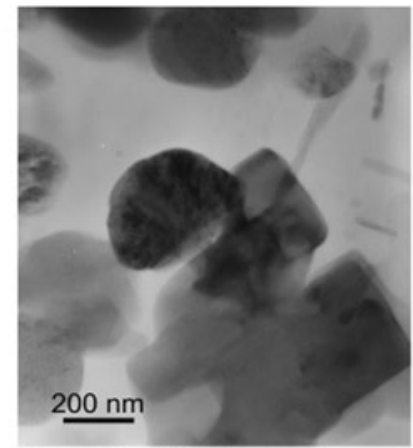

(b) $474^{\circ} \mathrm{C} 21 \mathrm{~min}$

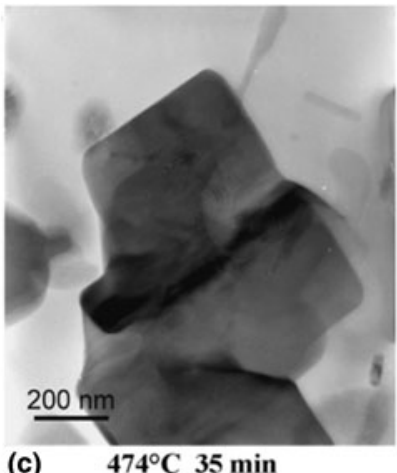

(c)

$474^{\circ} \mathrm{C} 35 \mathrm{~min}$

Figure 3: The decomposition of an icosahedral quasicrystalline phase from the Al-Fe- $\mathrm{Cr}$ system, by hot-stage TEM. The sample was heated to $474{ }^{\circ} \mathrm{C}$ (a) and held until the end of the decomposition reaction (b) and (c). It can be observed that the quasicrystalline phase was completely consumed by another intermetallic phase after $35 \mathrm{~min}$ of exposure in this temperature. Reprinted from Galano et al. [83]. Copyright (2009), with permission from Elsevier.

the high cooling rates that can be achieved using these fabrication techniques and the fact that most quasicrystals can only form upon rapid solidification. Melt-spinning can achieve one of the highest cooling rates during an alloy solidification due to the low thickness (usually around $30 \mu \mathrm{m}$ ) of the ribbons produced and the fact that they solidify on a high-speed rotating $\mathrm{Cu}$-wheel, thus being a key technique to study quasicrystal forming ability. $\mathrm{Cu}$-mold quenching (die-casting) can also achieve enough cooling rates to form metastable quasicrystals. However, the cooling rates are substantially lowered by the usual sample's thickness produced by this technique, in the range of $\mathrm{mm}$. Despite this limitation, fabricating the composites via die-casting can be very interesting since the samples are more adequate for mechanical testing and also, it is possible to vary the applied cooling rates (e.g., by using a wedge-shaped $\mathrm{Cu}$-mold), and thus monitor the limiting thickness from which a desired composite microstructure can be obtained.

As already mentioned, the first reported quasicrystalforming system, from Shechtman et al. [1], was observed in a melt-spun $\mathrm{Al}-\mathrm{Mn}$ alloy and naturally, the following quasicrystal-related studies were made in the same system. The first reported microstructures containing Al-FCC (facecentered cubic) and quasicrystals belong to the Al-Mn, Al$\mathrm{Mn}-\mathrm{Ce}$, and $\mathrm{Al}-\mathrm{Mn}-\mathrm{Fe}$ systems and were reported by Inoue et al. [78] and Schurack et al. [80]. In one of the mentioned studies [78], the alloys were fabricated by melt-spinning and showed tensile strengths above $1000 \mathrm{MPa}$. This outstanding mechanical strength led to many subsequent studies that aimed at improving processability and mechanical properties of these materials. In particular, one of the most interesting features presented by these composites was their ability to retain high percentages (around 60\%) of their room temperature yield strength when tested around $250{ }^{\circ} \mathrm{C}$, where the conventional high-strength $\mathrm{Al}$ alloys (7XXX and 2XXX series) would only retain about $10-30 \%$ [35]. The high-temperature mechanical strength depends on the thermal stability of the quasicrystal, on how long this phase can maintain its atomic structure and, equally importantly, on the nanometric particle size when it is submitted to these temperatures. Figure 3, adapted from Ref. [83], shows a hot-stage TEM (transmission electron microscopy) analysis of a melt-spun $\mathrm{Al}_{93} \mathrm{Fe}_{4.2} \mathrm{Cr}_{2.8}$ (\%at.) alloy, which forms nanoquasicrystalline particles [Fig. 3(a)] embedded in an Al-FCC matrix. In this analysis, the decomposition of the icosahedral phase, after heating the sample to $474{ }^{\circ} \mathrm{C}$ was noticed. It can be observed that a faceted squared-shaped particle nucleates from the rounded quasicrystal and after 35 min completely "consumes" the icosahedral phase.

In the recent literature, several authors have reported studies that aimed at finding alloying elements that would increase thermal stability of quasicrystals. Audebert, Galano and collaborators have performed extensive work on developing Al-FeCr-based alloys with nanoquasicrystalline phases embedded in an Al-FCC matrix with improved mechanical and thermal properties [7, 13, 35, 83, 84, 85]. The Al-Fe-Cr system forms nanometric icosahedral precipitates embedded in an Al-FCC matrix when rapidly solidified in specific chemical compositions, such as $\mathrm{Al}_{93} \mathrm{Fe}_{4.2} \mathrm{Cr}_{2.8}$ [13] (\%at.). The authors studied the effects of $\mathrm{Ti}, \mathrm{V}, \mathrm{Nb}$, and $\mathrm{Ta}$ additions on the formation of the icosahedral quasicrystal, its thermal stability, and mechanical properties among other features. It was found that partial substitution of $\mathrm{Fe}$ and $\mathrm{Cr}$ for one of the listed elements increased the quasicrystal thermal stability [83]. The stabilizing effect of these alloying elements on the quasicrystal structure can be understood in terms of a space frustration model of the icosahedral structure and from the thermal diffusivity of those elements in $\mathrm{Al}[13,84]$.

These stabilizing effects were experimentally confirmed by Audebert et al. [84] in melt-spun alloys with chemical compositions, indicated in Fig. 4. The X-ray diffraction (XRD) patterns show that as $\mathrm{Cr}$ and $\mathrm{Nb}$ alloying elements are added, the i-phase (icosahedral phase) reflections become more 


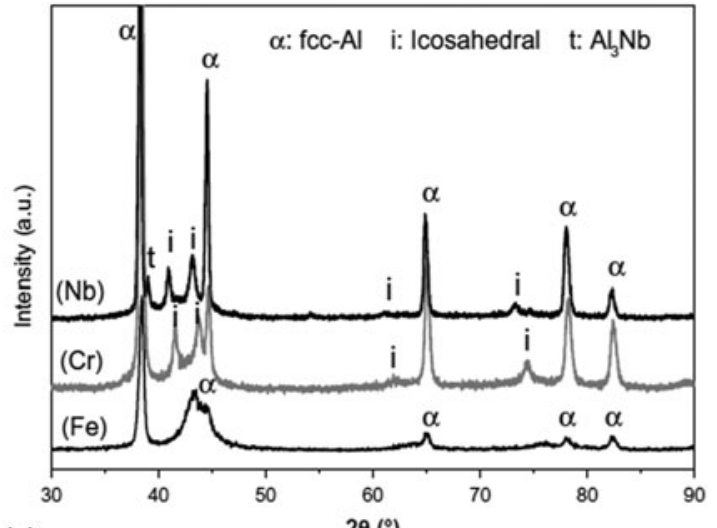

(a)

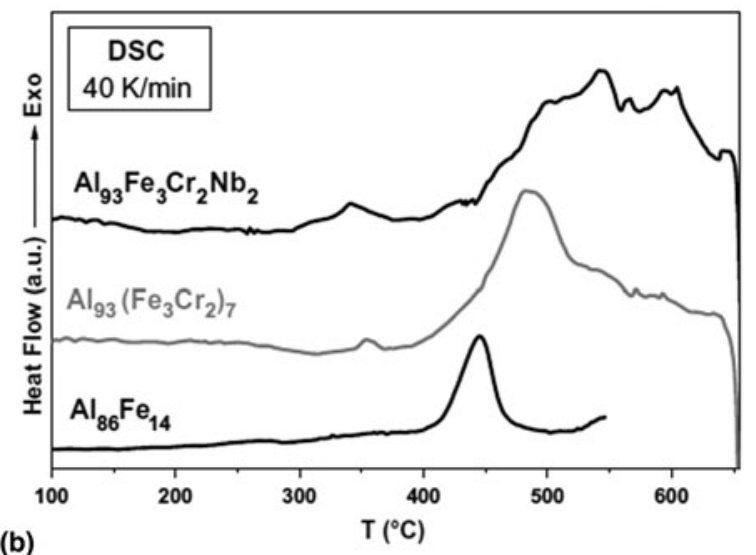

(b)

Figure 4: (a) XRD patterns of Al-Fe, Al-Fe-Cr, and $\mathrm{Al}-\mathrm{Fe}-\mathrm{Cr}-\mathrm{Nb}$ melt-spun alloys, showing that the icosahedral reflections are enhanced and better defined with alloying additions of $\mathrm{Cr}$ and $\mathrm{Nb}$ in the binary alloy. (b) DSC analysis from the same alloys, indicating that $\mathrm{Cr}$ and $\mathrm{Nb}$ additions increase the decomposition temperature of the quasicrystalline phase and extend it almost close to the alloy's melting temperature. Reprinted from Audebert et al. [84]. Copyright (2013), with permission from Elsevier.

defined and intense, indicating larger particle sizes and fractions. The differential scanning calorimetry (DSC) results show that the alloying elements increase the decomposition starting temperature of the quasicrystal.

In the studies conducted by this group, the melt-spun $\mathrm{Al}-\mathrm{Fe}-$ $\mathrm{Cr}-(\mathrm{M}=\mathrm{Ti}, \mathrm{V}, \mathrm{Nb}, \mathrm{T})$ alloys showed, at room temperature, similar ultimate tensile strength (UTS) values, ranging from 650 to $700 \mathrm{MPa}$ [52] and displayed virtually no plastic deformation. At elevated temperatures, the Ti-containing alloy performed better, maintaining UTS values above $400 \mathrm{MPa}$ even at $350^{\circ} \mathrm{C}$. However, all samples showed UTS values above $250 \mathrm{MPa}$ when tested at $350{ }^{\circ} \mathrm{C}$, which is substantially higher than what would be found for commercial high-strength $\mathrm{Al}$ alloys [35].

These findings indicate that $\mathrm{Ti}$ is probably the most interesting alloying element to be added to the $\mathrm{Al}-\mathrm{Fe}-\mathrm{Cr}$ quasicrystal-forming system. Not only does it show interesting thermal stability, but it also shows superior mechanical properties. In addition, if we look at melting temperatures of $\mathrm{Ti}, \mathrm{V}$, $\mathrm{Nb}$, and $\mathrm{Ta}$, we will find, respectively, 1660, 1890, 2468, and $3017^{\circ} \mathrm{C}$. Thus, in terms of processability, Ti addition seems to be very appealing due to its lower melting temperature, which would then facilitate fabrication of ingots and atomized powders of this material. We will discuss the development of gas-atomized powders and extruded alloys from the Al-FeCr-based system in the next subsection.

The Al-Mn system was also recently re-evaluated by different authors regarding alloying addition. Adding rare-earth elements, such as $\mathrm{Ce}$, was one of the first attempts to increase stability of the quasicrystalline phase [78]. However, a recent study by Coury et al. [34] showed, using electron microscopy, that $\mathrm{Ce}$ is virtually absent within the $\mathrm{Al}-\mathrm{Mn}$ quasicrystalline structure and its presence leads to the formation of a crystalline Al-Mn-Ce-based intermetallic. Stan-Głowińska et al. assessed the influence of $\mathrm{Fe}$ addition to the Al-Mn quasicrystal [36,
$86,87]$. The authors used wedge die-casting $[86,87]$ to evaluate the limiting thickness and cooling rates necessary to obtain refined quasicrystalline particles embedded in an Al-matrix. They showed that the Fe-containing alloys could form this microstructure if cooling rates in the order of $10^{3} \mathrm{~K} / \mathrm{s}$ were applied, resulting in a limiting thickness for this composite microstructure between $600 \mu \mathrm{m}$ and $1 \mathrm{~mm}$. The binary alloy (Al-Mn), on the other hand, did not show the formation of the icosahedral phase in the cast samples, which is a strong indicative that $\mathrm{Fe}$ enhances the stability and facilitates the formation of the quasicrystalline phase. The authors also studied the influence of Mo and $\mathrm{V}$ addition to the Al-Mn-Fe alloy using melt-spinning to fabricate the samples [36]. Both Mo and $\mathrm{V}$ additions resulted in quasicrystal-containing alloys (as for the ternary sample) and it was demonstrated that these elements can further enhance the stability of the quasicrystalline phase. This was shown by subsequent hot-compaction of the melt-spun alloys at $390^{\circ} \mathrm{C}$. Only the quaternary alloys retained the quasicrystalline phase after the sintering process, indicating that further alloying addition to the Al-Mn-based quasicrystal is potentially interesting for designing new alloy compositions. Naglič and collaborators [88, 89] showed that adding $\mathrm{Cu}, \mathrm{Mg}$, and $\mathrm{Si}$ to the binary $\mathrm{Al}-\mathrm{Mn}$ quasicrystal-forming alloy led to the formation of quasicrystals on Cu-mold quenched samples with a thickness of about $5 \mathrm{~mm}$. This represents a substantial increase in the processability of these alloys, allowing fabrication of relatively thick-walled materials with composite microstructure.

\section{MMCs produced by gas-atomization and powder metallurgy}

Although melt-spinning and $\mathrm{Cu}$-mold quenching liquid metals are two of the most important laboratory techniques used to study phase formation and mechanical properties of 
quasicrystalline composites, using them for mass production and technological applications is limited. Gas-atomization, on the other hand, is a well-established manufacturing process, which can supply the cooling rates required to obtain nanoquasicrystals embedded in the Al-FCC matrix.

Audebert et al. [35] fabricated Al-Fe-Cr-Nb alloys by gas-atomization and discussed the difficulties that arise when alloying elements with different melting temperatures, especially $\mathrm{Al}$ and $\mathrm{Nb}$. The authors used an $\mathrm{Fe}-\mathrm{Nb}$ pre-alloy to facilitate the melting process and three different thermal conditions (temperature that the alloy was melted and the holding time in that temperature). One of the main issues that the authors found was related to chemical composition control, especially in reaching the targeted $\mathrm{Al}$ and $\mathrm{Nb}$ contents. Nonetheless, the authors showed that for specific atomization conditions, this alloy's powder can be fabricated with the desired microstructure. Another important result was related to the particle size above which no icosahedral phase forms. They showed that for powder particles above $175 \mu \mathrm{m}$, no quasicrystalline particles were identified. In addition, particles below $75 \mu \mathrm{m}$ were the ones with higher quasicrystalline phase content. In the same study, the atomized powders were subsequently extruded at $375^{\circ} \mathrm{C}$. This condition was chosen based on previous studies of this alloy that showed no decomposition of the icosahedral phase at this temperature [13]. The authors showed that the powder microstructure was preserved in the extruded material.

Prior to the above-mentioned work, Todd et al. [90] showed that it is possible to fabricate $\mathrm{Al}_{93} \mathrm{Fe}_{3} \mathrm{Cr}_{2} \mathrm{Ti}_{2}$ products by gas-atomization and hot-extrusion. Only powders with particle size $<100 \mu \mathrm{m}$ were analyzed in that study and the authors showed that with reducing powder size, the icosahedral phase reflections on XRD patterns presented higher intensity and were better defined. The powder sizes below $50 \mu \mathrm{m}$ yielded larger fractions of the quasicrystalline phase. The authors studied the influence of several extrusion parameters and the initial powder size in the final mechanical properties. Tensile tests showed that using initial powder sizes ranging between 25 and $50 \mu \mathrm{m}$ led to yield stress values around $500 \mathrm{MPa}$, UTS values close to $600 \mathrm{MPa}$ and elongation close to $6 \%$ at room temperature.

Although $\mathrm{Al}-\mathrm{Fe}-\mathrm{Cr}$-based extruded alloys were proven to show high strength at room and elevated temperatures, one of the main drawbacks is the lower ductility that they present under tension, when compared to commercial high-strength $\mathrm{Al}$ alloys [91]. Aiming to improve the extruded Al-Fe-Cr-Ti alloy's ductility, Pedrazzini et al. [91] fabricated composites of the quasicrystalline alloy with fractions of pure Al fibers that were mixed with the atomized alloy prior to the extrusion process. The authors showed that with no $\mathrm{Al}$ fiber addition, the extruded alloy showed, under tensile tests at room temperature, a yield stress of $544 \mathrm{MPa}$ and elongation of $6.4 \%$ while $10-20 \%$ volumetric additions of pure $\mathrm{Al}$ fibers, enhanced the elongation to $7.4 \%$ at a cost of yield stress reduction to $481 \mathrm{MPa}$.

Interesting recent developments have been published on rapidly solidified $\mathrm{Al}-\mathrm{Cr}-\mathrm{Mn}-\mathrm{Co}-\mathrm{Zr}$ alloys, firstly reported by Watson et al. [92]. In this first publication, the authors studied nanoquasicrystalline phase formation on gas-atomized powders of an alloy with the following composition: $\mathrm{Al}_{93.8} \mathrm{Cr}_{2.6} \mathrm{Co}_{1.6} \mathrm{Mn}_{1.5} \mathrm{Zr}_{0.5}$ (\%at.). The powders, with particle size inferior to $34 \mu \mathrm{m}$, showed a microstructure composed mainly by an icosahedral phase and the Al-FCC matrix. The powder samples were blind die compacted at $310^{\circ} \mathrm{C}$ and then forged at temperatures ranging from 260 to $315^{\circ} \mathrm{C}$, resulting in cylindrical parts with a height reduction of $90 \%$. The mechanical properties of the forged composite were assessed by tensile tests in different temperatures. At room temperature, the samples showed tensile yield strength of $690 \mathrm{MPa}$ and elongation of $6 \%$. At $315^{\circ} \mathrm{C}$, samples showed yield strength of $400 \mathrm{MPa}$ and $10 \%$ of elongation. Achieving a significant reduction through forging processes is an important improvement toward future applications of these composite materials. The mechanical properties displayed by this composite appear to be enhanced in relation to the previously discussed works. This is a consequence of the forging process, which can effectively improve the reinforcing phase distribution though the Al-matrix [Fig. 5(a)], yielding an optimized material for mechanical strength and ductility.

Following the advances brought by Watson and collaborators, Leonard et al. $[75,93]$ have further improved the ductility and processability of the $\mathrm{Al}-\mathrm{Cr}-\mathrm{Co}-\mathrm{Mn}-\mathrm{Zr}$ quasicrystalline composites, studying the influence of $\mathrm{Cr}-\mathrm{Co}-\mathrm{Mn}-\mathrm{Zr}$ content and forging parameters on the microstructure and mechanical properties of these alloys. In their recent work [93], three different compositions of the $\mathrm{Al}-\mathrm{Cr}-\mathrm{Co}-\mathrm{Mn}-\mathrm{Zr}$ system were fabricated by gas-atomization, subsequently blind die compacted at $310{ }^{\circ} \mathrm{C}$ and then forged at different temperatures and reductions. The particle size used in this work was below $40 \mu \mathrm{m}$. The forging parameters evaluated were temperature $(300,315,330$, 345 , and $370{ }^{\circ} \mathrm{C}$ ) and height reduction from cylindrical samples (30\%, 50\%, 70\%, and 90\%). Figure 5(b) shows the blind die compacted samples and the cylindrical cuts from which the forging samples were removed. Figures 5(c)-5(g) show the samples after different forging steps. Figures 5(c) and 5(d) show the samples after $30 \%$ reduction (axial and slide views, respectively). Figures $5(\mathrm{e})-5(\mathrm{~g})$ show slide views of the samples after $50 \%, 70 \%$, and $90 \%$ reductions, respectively. The authors showed that there was no decomposition of the quasicrystalline phase during the thermomechanical processes applied and for the samples with large height reduction a more refined microstructure was obtained where the large quasicrystalline particles were fractured and better dispersed in the Al-matrix. This 

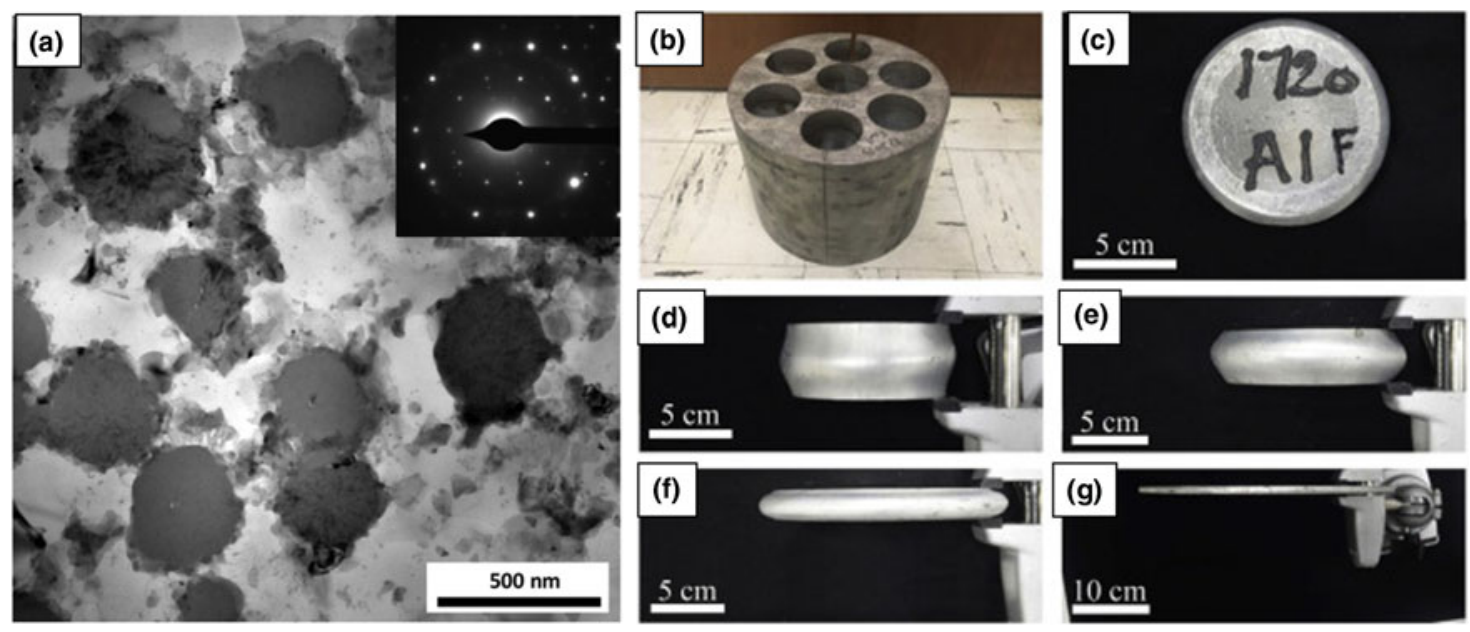

Figure 5: (a) TEM micrograph and electron diffraction pattern of the $\mathrm{Al}_{93.8} \mathrm{Cr}_{2.6} \mathrm{Co}_{1.6} \mathrm{Mn}_{1.5} \mathrm{Zr}_{0.5}$ forged alloy. The electron diffraction pattern confirms the icosahedral symmetry of the quasicrystalline particles. (b) Blind die compacted samples (of Al-Cr-Co-Mn-Zr alloys) and the cylindrical cuts for producing the initial forging samples. (c) Axial view of a forged sample (30\% height reduction). (d-g) Slide views of the forged samples after (d) $30 \%$, (e) $50 \%$, (f) $70 \%$, and (g) $90 \%$ of height reduction. (a) Reprinted from Watson et al. [92]. Copyright (2016), with permission from Elsevier. (b-g) Reprinted from Leonard et al. [93]. Copyright (2020), with permission from Elsevier.

effectively enhanced the elongation displayed by the composites, under tensile tests, to values up to $\sim 15 \%$ at room temperature. The samples yielding these large elongation values, displayed tensile yield strength around $450 \mathrm{MPa}$. These results suggest a feasible processing route to obtain quasicrystalline composites with improved ductility, which is one of the most important issues holding back their applications and thus are very promising. The latest publication of the same research group, by Rommel et al. [94], evaluated the corrosion resistance of this powder-processed Al-based composite in $\mathrm{NaCl}$ solution. The authors studied the effects of the initial powder particle size and phase constitution on the corrosion severity and concluded that the composite shows good corrosion resistance in the conditions studied.

Recent advances on additive manufacturing processes of metallic materials have also opened up new possibilities for fabricating MMCs reinforced with quasicrystals. This is because most of the manufacturing processes are based on laser sintering of metallic powders, such as selective laser melting (SLM), which can yield high cooling rates (necessary to form most quasicrystals) and produce geometrical complex products. Kang et al. [77, 95] have made interesting studies on fabrication of in situ icosahedral $\mathrm{Al}-\mathrm{Fe}-\mathrm{Cr}$ quasicrystals by mixing pure $\mathrm{Al}$ powders with $\mathrm{Al}-\mathrm{Cu}-\mathrm{Fe}-\mathrm{Cr}$ decagonal quasicrystals and then using the SLM process. The formation of the icosahedral Al$\mathrm{Fe}-\mathrm{Cr}$ quasicrystal took place after the mixed powders were melted and then rapidly solidified. Kairy et al. [96] observed the formation of $\mathrm{Mg}-\mathrm{Cu}-\mathrm{Zn}$-based nanometric quasicrystals during the SLM process of an AA7075 aluminum alloy, which had never been observed previously. This is extremely interesting because it allows, from a commercially available material, fabrication of these composites using additive manufacturing processes. There is a relatively limited number of studies using additive manufacturing for processing MMCs reinforced with quasicrystals. Thus, this could be an exciting area to be explored and that could yield future technological applications of these materials.

\section{Al-Matrix MMCs Reinforced with Micron-Sized Quasicrystals}

\section{MMCs produced by powder metallurgy}

Quasicrystals that can be fabricated with or without rapid solidification are, as already mentioned at the beginning of this review, sometimes referred to as the "stable" ones. They are particularly interesting because their processing can be less expensive and, in principle, more flexible. However, these quasicrystalline phases usually form in narrow composition ranges and are surrounded by several intermetallic phases, take the $\mathrm{Al}-\mathrm{Cu}-\mathrm{Fe}$ phase diagram [97] as an example. These two issues complicate the process because when a quasicrystal-forming alloy composition is cast, the microstructures obtained are usually multi-phased, which leads to a brittle material. In addition, most of the known quasicrystal-forming alloys do not form from casting a two-phase microstructure with the quasicrystal in equilibrium with a solid solution, such as Al-FCC.

The $\mathrm{Al}-\mathrm{Cu}-\mathrm{Fe}$ system is a good example to explain this condition. Between the compositions of the icosahedral phase and the Al-FCC, a third phase, $\omega-\mathrm{Al}_{7} \mathrm{Cu}_{2} \mathrm{Fe}$, does not allow the formation of the microstructure containing Al-FCC and quasicrystal. The same issue is found in most of the known quasicrystal-forming systems [32]. This is the reason why almost all the studies on Al-matrix composites reinforced 
with "stable" quasicrystals are based on obtaining a powder of the quasicrystalline alloy, then fabricating the composite by mixing this material with a ductile second phase (e.g., Al powder) and consolidating it, usually by sintering processes.

Tsai et al. [98] were the first to report the fabrication of an Al-matrix composite reinforced with $\mathrm{Al}-\mathrm{Cu}-\mathrm{Fe}$ quasicrystals by ball-milling this phase with $\mathrm{Al}$ powder. The mixtures were then hot pressed to consolidate the composite. In this work, different volumetric proportions of the reinforcing phase and two different sintering temperatures were used (400 and $600^{\circ}$ C). The authors observed a transformation of the icosahedral phase to the $\omega-\mathrm{Al}_{7} \mathrm{Cu}_{2} \mathrm{Fe}$ during sintering at $600{ }^{\circ} \mathrm{C}$. This phase transformation occurs because the $\omega$-phase is in between $\mathrm{Al}-\mathrm{FCC}$ and the quasicrystal in the phase diagram and the high temperatures applied in the sintering process led to Al diffusion into the quasicrystal resulting in its decomposition.

Following this first publication, other studies have been published focusing on the possible fabrication methods to obtain these composites and on their mechanical properties [99, 100, 101, 102, 103, 104]. Bonneville and collaborators have performed extensive studies on Al-matrix composites reinforced with $\mathrm{Al}-\mathrm{Cu}-\mathrm{Fe}$ particles [102, 105, 106, 107]. The authors have used several different processing routes such as a hot isostatic pressing (HIP) process [102], spark plasma sintering (SPS) [106], and gas-pressure infiltration [108] to study microstructural evolution and mechanical properties of the composites. Ali, Scudino and collaborators have also contributed with important studies on the mechanical properties of hot-extruded Al-matrix composites reinforced with $\mathrm{Al}-\mathrm{Cu}-\mathrm{Fe}$ particles [101, 109].

One common aspect of all the above studies is that, depending on the consolidation temperature, the quasicrystalline reinforcing phase can partially or completely transform to the $\omega-\mathrm{Al}_{7} \mathrm{Cu}_{2} \mathrm{Fe}$ phase. According to Tsai et al. [98], sintering above $600{ }^{\circ} \mathrm{C}$ leads to complete transformation of the icosahedral phase. Subsequent studies have monitored this reaction in detail in the consolidated samples [101, 106]. This phase transformation was shown to be beneficial for the mechanical properties. This is because the $\omega$-phase has a lower density than the quasicrystal, which results in a volumetric expansion of the reinforcing particles within the Al-matrix, improving interfacial bonding between the particles and the matrix and introducing compressive stresses in the ductile matrix [101].

Figure 6 shows examples of the typical microstructures obtained in $\mathrm{Al}+\mathrm{Al}-\mathrm{Cu}-\mathrm{Fe}$ composites. In Fig. 6(a), the composite was fabricated by uniaxial hot pressing followed by hot extrusion [109]. Figure 6(b) shows a composite that was fabricated by uniaxial hot pressing [103]. Figure 6(c), on the other hand, shows the fabrication of the composite by gas-pressure infiltration of the quasicrystalline powder in molten $\mathrm{Al}$ [108].
This is a different process where the quasicrystal phase is added to the liquid matrix which is then solidified. Other authors have also tried this approach [110, 111]; however, they report a complex microstructure formed after matrix solidification due to partial dissolution of the quasicrystalline particles. Figure 6(d) shows a composite microstructure fabricated by hot-extrusion [70]. This latter microstructure shows wavelike patterns of the reinforcing phase. This microstructure resulted from the high energy ball mixing of the $\mathrm{Al}$ and quasicrystalline powders, which led to a flattening of the Al powder increasing its surface area, where fine quasicrystalline particles could adhere, prior to the extrusion process.

The strengthening mechanisms of the reinforcing quasicrystalline particles in the above-referred cases are significantly different than the ones from the rapid-solidified quasicrystals (previous section). The reinforcing particle sizes are much coarser in the stable-quasicrystal composites because the microstructure is fabricated ex situ, that is, quasicrystals and ductile matrix are fabricated separately, mixed, and then consolidated. The reinforcing particles in these composites are in the micron-size range. This means that most of the strengthening effects of these quasicrystalline particles are based on load transfer from the matrix to the particle and secondary strengthening due to dislocation interactions and multiplication as a consequence of introduced interfacial stresses between matrix and particles [99, 109]. Orowan strengthening can also occur if submicrometric particles are involved, which is a minor effect in the case of composites such as the ones from Fig. 6 [99].

The consequence of this coarser microstructure is that the mechanical strength of these composites is inferior to the ones reinforced with rapid-solidified quasicrystals. This can be seen by the substantially lower tensile yield stresses of these materials (usually lower than $200 \mathrm{MPa}$ [99] at room temperature) and further supported by the fact that most mechanical tests reported in these studies were performed using compression. This is because the large and brittle quasicrystalline particles act as stress concentration that will lead to the low tensile strength observed. Compressive yield strength in the range of 300-400 $\mathrm{MPa}$ were reported for $\mathrm{Al}+\mathrm{Al}-\mathrm{Cu}-\mathrm{Fe}$ composites with a volume of particle reinforcement in the range of 40 $60 \%[102,109]$, at room temperature.

Although most of the studies about MMCs reinforced with stable quasicrystals are based on the $\mathrm{Al}-\mathrm{Cu}-\mathrm{Fe}$ system, a few have also fabricated Al-matrix composites reinforced with Al-Pd-Mn-based quasicrystals using hot extrusion [70] and $\mathrm{Al}-\mathrm{Cu}-\mathrm{Cr}-\mathrm{Fe}-$ based quasicrystals using SPS or uniaxial compression $[112,113,114]$. In these studies, the same type of coarse particle reinforcement was observed.

Thus, applications of these composites as high-strength materials do not seem feasible and this is mostly due to the difficulties in obtaining a refined dispersion of the reinforcing 


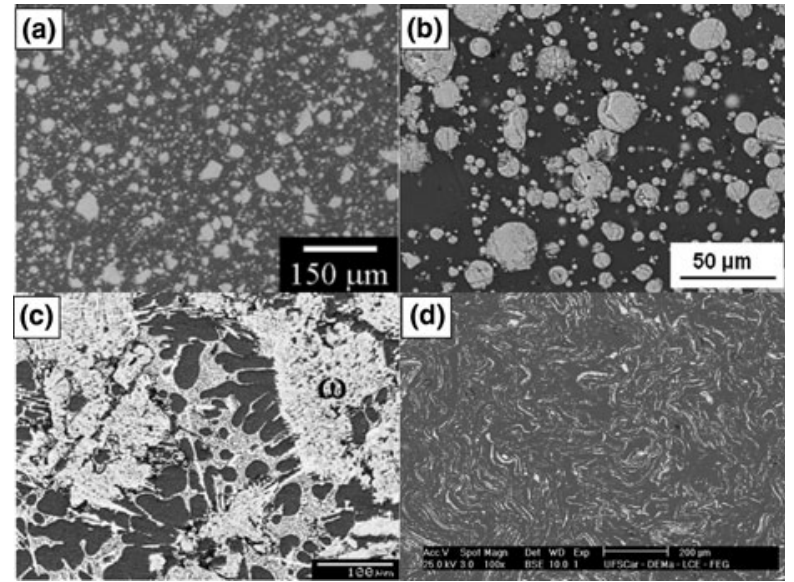

Figure 6: $\mathrm{Al}+\mathrm{Al}-\mathrm{Cu}-\mathrm{Fe}$ composites fabricated by (a) uniaxial hot-pressing and subsequently hot-extrusion, (b) uniaxial hot-pressing, (c) gas-pressure infiltration of Al-Cu-Fe particles in a molten Al-alloy, and (d) hot-extrusion of highenergy ball-milled powder composites. (a) Reprinted from Ali et al. [109]. Copyright (2011), with permission from Elsevier. (b) Reprinted from Dobrzyńska et al. [103], Copyright (2015), with permission from Elsevier. (c) Reprinted from Laplanche et al. [108]. Copyright (2009), with permission from Elsevier. (d) Reprinted from Wolf et al. [70], licenced under CC BY-ND 4.0 (http://creativecommons.org/licenses/by/4.0/).

phase. However, applying these materials for tribological protection is one possible way of using a few of the unique properties of quasicrystals.

\section{MMCs produced by slow solidification/ conventional processing}

As already stated, some quasicrystal systems can be produced using conventional metallurgical processes because they can be obtained using slow solidification. Composite processing, on the other hand, is more complicated because it would require finding a quasicrystal-forming system that shows a phase field with stability between Al-FCC and the quasicrystal. If that did not exist, then the methods for obtaining such composites would be only the ones described in the previous subsection.

In a recent publication, Wolf et al. [72] have shown, experimentally, that the $\mathrm{Al}-\mathrm{Cu}-\mathrm{Fe}-\mathrm{Cr}$ system can form this two-phase co-existence between a decagonal quasicrystal and Al-FCC in a cast alloy. In that study, an $\mathrm{Al}_{85} \mathrm{Cu}_{6.75} \mathrm{Fe}_{3.375} \mathrm{Cr}_{4.875}$ (\%at.) alloy ingot was cast and then annealed at $600{ }^{\circ} \mathrm{C}$ for $10 \mathrm{~h}$. The resulting microstructure contained, in volumetric percentages, $48.7 \%$ of decagonal quasicrystals, $43.5 \%$ of Al-FCC, and $7.8 \%$ of $\omega-\mathrm{Al}_{7} \mathrm{Cu}_{2} \mathrm{Fe}$. The decagonal phase formed during the annealing step from a peritectic reaction between a liquid phase (formed from the eutectic $\mathrm{Al}-\mathrm{Al}_{2} \mathrm{Cu}$ of the as-cast ingot) and a quaternary $\mathrm{Al}-\mathrm{Cr}$-rich intermetallic phase that forms as a primary phase in this alloy when solidified under slow cooling rates [71]. Figure 7 shows TEM images that identified and confirmed this

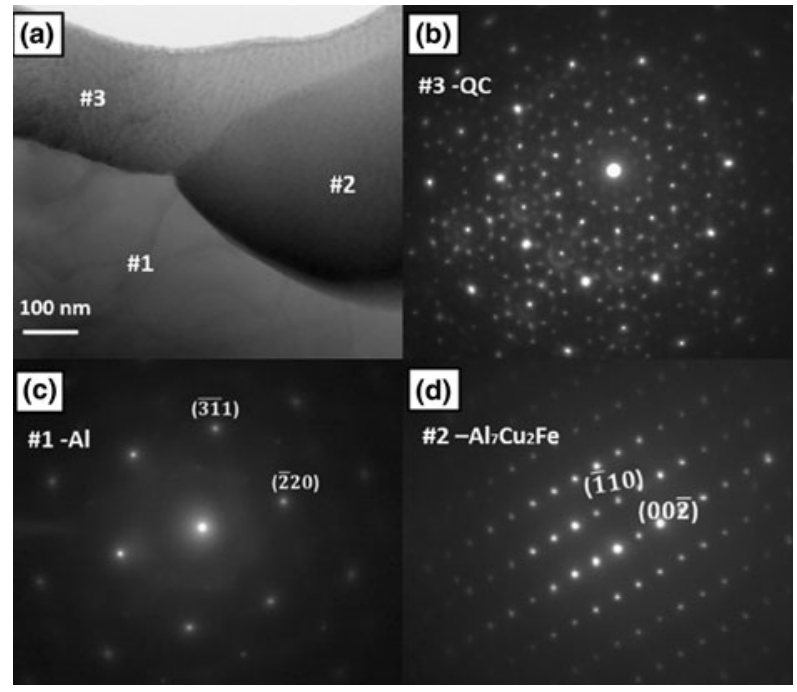

Figure 7: TEM micrographs of the cast and annealed $\mathrm{Al}_{85} \mathrm{Cu}_{6.75} \mathrm{Fe}_{3.375} \mathrm{Cr}_{4.875}$ alloy with the phase identification by electron diffraction of the phases that composes the composite microstructure. (a) Bright field micrograph displaying the alloy's microstructure. Electron diffraction patterns taken from the quasicrystalline (b), Al-FCC (c), and $\mathrm{Al}_{7} \mathrm{Cu}_{2} \mathrm{Fe}$ (d) phases. Reprinted from Wolf et al. [72]. Copyright (2019), with permission from Elsevier.

microstructure. This was the first time such a composite microstructure was obtained using only conventional metallurgical processes.

This work brought important outcomes to the development of Al-matrix composites reinforced with quasicrystals because they can now be fabricated virtually by any metallurgical method. For instance, large-scale fabrication of these MMCs can be obtained by conventional casting ingots if a proper annealing step is also performed. Thus, tons of this composite material may be fabricated using the alloy developed in that work, which was virtually impossible in any of the previously known quasicrystal-reinforcing composites. In addition to the processing improvements, the reinforcing particle/matrix interface is probably stronger in this case because the metallurgical bonds between the phases were formed during solidification as opposed to the sintered products by powder metallurgy. The microstructure obtained using conventional casting will consist of large quasicrystalline particles, which can be used against wear and friction, but are not quite optimal for mechanical strength. In the latter case, the quasicrystal particles will need to be refined.

Metastable processing can also be used to fabricate the Al$\mathrm{Cu}-\mathrm{Fe}-\mathrm{Cr}$-based composites because the decagonal phase formation is facilitated under rapid solidification conditions. The same phases found after annealing of the cast ingot, were formed when a similar alloy was gas-atomized [71], without further need for thermal treatments. In addition, the microstructure was more refined in the atomized powders. This also opens up possibilities for additive manufacturing of this 


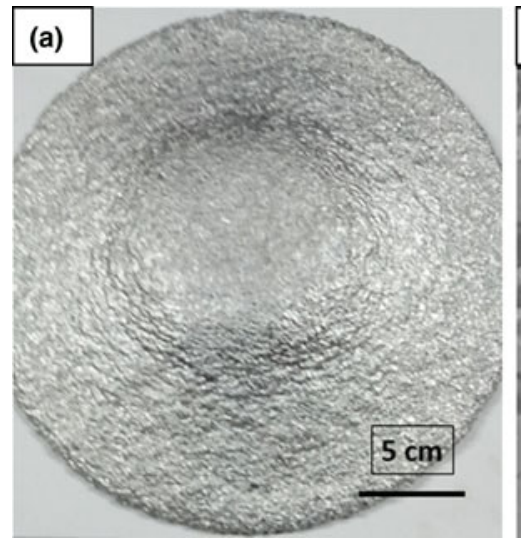

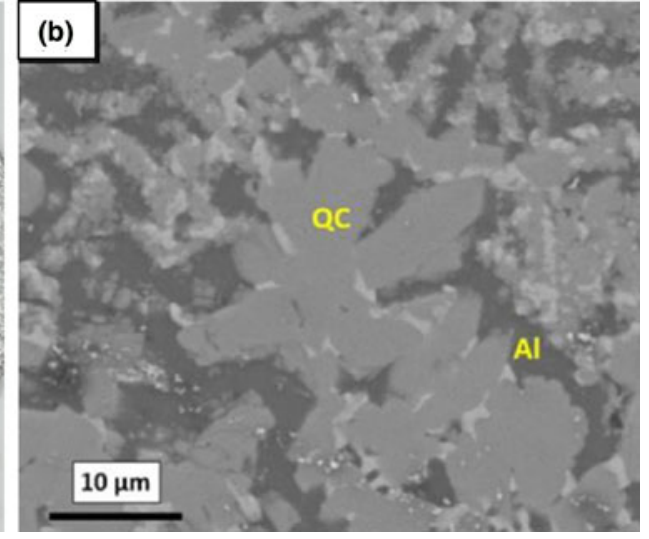

Figure 8: (a) 2 kg spray formed composite with (b) microstructure consisting mainly of Al-FCC and quasicrystals. Reprinted from Wolf et al. [71]. Copyright (2020), with permission from Elsevier. alloy, in the sense that the final microstructure is probably going to be very refined and possibly present high-mechanical strength. However, this hypothesis has not been tested yet.

The spray-forming technique was also used to fabricate this composite and the quasicrystal phase was formed directly during solidification with no need of further thermal treatments to obtain the Al-FCC + quasicrystal microstructure in the bulk material. Figure 8 (a) shows a $\sim 2 \mathrm{~kg}$ composite sample, fabricated in a single processing step, by spray forming an $\mathrm{Al}_{85} \mathrm{Cu}_{6} \mathrm{Fe}_{3} \mathrm{Cr}_{6}$ (\%at.) alloy. This sample was obtained directly from the melt during the solidification process and contained mainly the decagonal quasicrystal and Al-FCC phases [Fig. 8 (b)]. This was a result from the solidification mechanisms of the spray-forming process. The atomized droplets that were completely or partially solidified during spraying of the metallic stream contained the decagonal phase, which forms as a primary phase upon rapid solidification [71]. When these droplets impinge the deposit being formed, they can be totally or partially re-melted. Considering the particles that were only partially re-melted, they will contain the decagonal phase that will then act as an inoculant for the further growth of this phase. Because of the spray-forming process characteristics, the material displays a coating-like microstructure (layered microstructure with porosity) and the low solidification rates the bulk material experienced during deposition led to formation of large quasicrystalline particles, which are appropriate for applications of this material on protection against wear and friction.

The sliding wear behavior of the sprayed composite was assessed by pin-on-disk tests which showed a superior performance of this material in comparison to an Al-Si A380 alloy when tested in two different conditions, showing half of the wear rate experienced by the Al-Si alloy. The coefficient of friction shown by the composite was also lower than the Al-Si alloy. In addition, the authors have shown in a recent publication [115] that this composite has a significantly improved (two times higher) wear resistance when compared to a singlephased $\mathrm{Al}-\mathrm{Cu}-\mathrm{Fe}-\mathrm{Cr}$ decagonal quasicrystal fabricated by high velocity oxygen fuel spraying (HVOF). Most of the previously published wear-related studies on quasicrystalline materials are based on single-phased (or nearly single-phased) quasicrystals $[5,69,116]$ and, although interesting results have been reported, the brittleness of the quasicrystalline phase leads to a transition on the behavior of these materials under sliding wear, depending on the load applied. However, adding a ductile second phase to its microstructure can reduce their load sensitivity, yielding materials and coatings with improved wear resistance.

\section{Opportunities for Future Research}

Based on the literature review performed in this work, potentially interesting opportunities for new research on the development of Al-matrix quasicrystalline composites can be associated with:

(i) The development of the next generation of high-strength aluminum alloys with appropriate ductility for application at room temperature, and especially at high temperatures, related to the Al-Cr-Mn-Co- $\mathrm{Zr}$ alloy. As discussed, this alloy can be processed by many thermomechanical methods and can yield materials with improved ductility at room temperature yet maintaining high values of tensile strength. There is room for research on the development and optimization of the manufacturing processes, especially regarding gas-atomization and thermomechanical processing, which are not trivial and decisive for the success of applying this material.

(ii) The $\mathrm{Al}-\mathrm{Cu}-\mathrm{Fe}-\mathrm{Cr}$ system also appears among the most promising ones. Since it can be fabricated using virtually any metallurgical process, developing a viable casting procedure for obtaining high-quality MMCs can lead to improved tribological properties. In addition, there is room for assessing new compositions with different fractions of quasicrystal content depending on the alloy's 

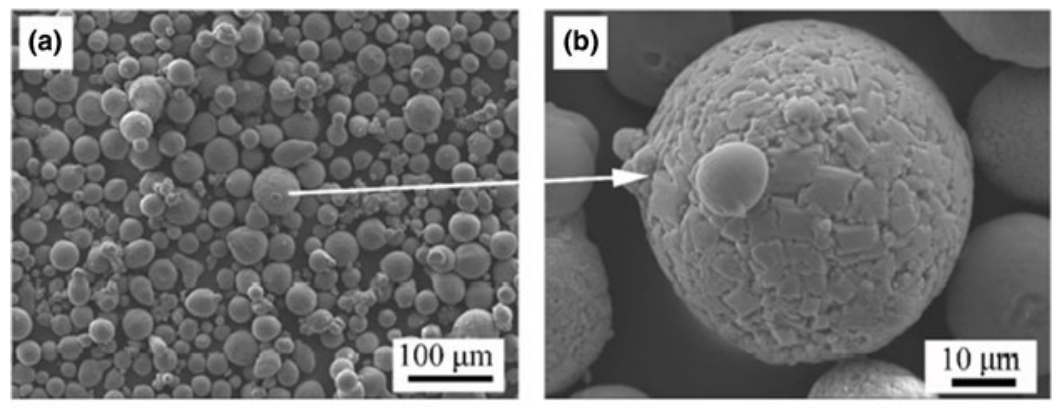

Figure 9: Al-matrix composite reinforced with Al-Fe$\mathrm{Cr}$ quasicrystals, fabricated in situ by SLM a powder mixture of $\mathrm{Al}-\mathrm{Cu}-\mathrm{Fe}-\mathrm{Cr}$ quasicrystals and $\mathrm{Al}(\mathrm{a}, \mathrm{b})$. (c) Simple and (d) complex shapes can be fabricated by SLM. Reprinted from Kang et al. [95]. Copyright (2018), with permission from Elsevier.

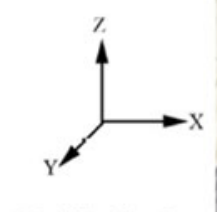

Z: building direction

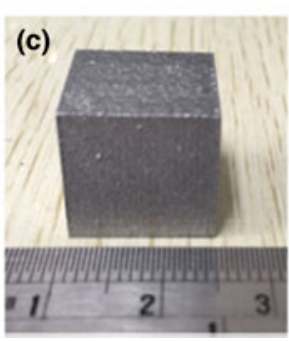

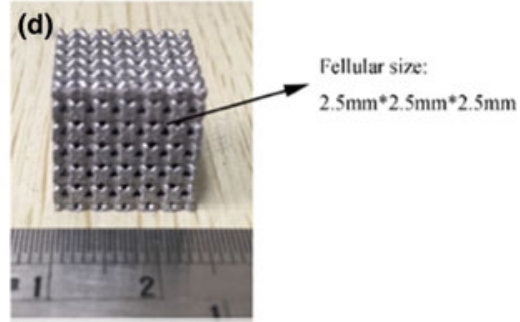

composition. Another key point for further developing this MMC is to refine the quasicrystal particles, which can lead to improved mechanical strength.

(iii) Technological applications of quasicrystalline-based coatings and surfaces with improved wear resistance are probably restricted to adding a ductile second phase to balance the quasicrystal's brittleness. There are many possible ways for obtaining this microstructure. The Al$\mathrm{Cu}-\mathrm{Fe}-\mathrm{Cr}$ system is a very appealing one because the composite microstructure can be obtained as a coating or a bulk material, opening up several possibilities for processing strategies. Cold spraying metastable quasicrystals embedded in $\mathrm{Al}$-matrix, such as the $\mathrm{Al}-\mathrm{Cr}-$ $\mathrm{Mn}-\mathrm{Co}-\mathrm{Zr}$ alloy, is also a promising way to obtain these wear-resistant materials.

(iv) Additive manufacturing: the new manufacturing processes introduced for 3D printing metals, such as SLM, can be effectively used to fabricate MMCs reinforced with quasicrystals. The high cooling rates that can be achieved, make it possible to fabricate refined microstructures, which would, in turn, result in high-strength materials. In addition, the possibilities of fabricating complex shapes from gas-atomized powders (Fig. 9) and the significant industrial interest make this manufacturing process even more attractive.

\section{Concluding Remarks}

Quasicrystals certainly have unique properties that are of interest in many areas and, although technological applications of these materials have encountered several drawbacks, the latest achievements reported in the literature points out, in the author's opinion, an optimistic scenario for the next studies on the developments of new Al-matrix composites with improved properties and processability.

Recent developments in improving high-strength $\mathrm{Al}$ alloy compositions and processing routes can catalyze their application, especially at high temperatures, where commercial $\mathrm{Al}$ alloys cannot be used and Ti alloys are used instead. These highstrength quasicrystalline composites could certainly be applied in these cases if their mechanical properties and processing methods are adequate (and financially advantageous). This has been the focus of recent studies on these high-strength $\mathrm{Al}$ alloys. The recent discovery of the viability for producing, on a large scale, ingots of Al-matrix composites reinforced with $\mathrm{Al}-\mathrm{Cu}-$ Fe-Cr quasicrystals can, on the other hand, catalyze their use in applications such as tribological and thermal protection.

\section{Acknowledgments}

The authors thank the institutional and financial support received over several years to research quasicrystalline alloys and composites, in particular, Fundação de Amparo à Pesquisa do Estado de São Paulo (FAPESP), Conselho Nacional de Desenvolvimento Científico e Tecnológico (CNPq), Coordenação de Aperfeiçoamento de Pessoal de Nível Superior (CAPES), Universidade Federal de São Carlos (UFSCar), and Universidade Federal de Minas Gerais (UFMG). We also thank the colleagues in Brazil and abroad that have contributed to our quasicrystal-related studies.

\section{References}

1. D. Shechtman, I. Blech, D. Gratias, and J.W. Cahn: Metallic phase with long-range orientational order and no translational symmetry. Phys. Rev. Lett. 53, 1951 (1984). 
2. E. Huttunen-Saarivirta: Microstructure, fabrication and properties of quasicrystalline $\mathrm{Al}-\mathrm{Cu}-\mathrm{Fe}$ alloys: A review. J. Alloys Compd. 363, 154 (2004).

3. L. Bindi, N. Yao, C. Lin, L.S. Hollister, C.L. Andronicos, V.V. Distler, M.P. Eddy, A. Kostin, V. Kryachko, G.J. MacPherson, W.M. Steinhardt, M. Yudovskaya, and P.J. Steinhardt: Natural quasicrystal with decagonal symmetry. Sci. Rep. 5, 9111 (2015).

4. P.J. Steinhardt: Solid-state physics: How does your quasicrystal grow? Nature 452, 43 (2008).

5. J-M. Dubois: Properties and applications of quasicrystals and complex metallic alloys. Chem. Soc. Rev. 41, 6760 (2012).

6. A. Inoue, H. Kimura, and T. Masumoto: Formation, thermal stability and electrical resistivity of quasicrystalline phase in rapidly quenched Al-Cr alloys. J. Mater. Sci. 22, 1758 (1987).

7. M. Galano, F. Audebert, B. Cantor, and I. Stone: Structural characterisation and stability of new nanoquasicrystalline Al-based alloys. Mater. Sci. Eng. A 375-377, 1206 (2004).

8. A-P. Tsai, A. Inoue, and T. Masumoto: A stable quasicrystal in Al-Cu-Fe system. Jpn. J. Appl. Phys. 26, L1505 (1987).

9. A.P. Tsai, A. Inoue, and T. Masumoto: Stable Decagonal Al-Co-Ni and Al-Co-Cu Quasicrystals. Mater. Trans. JIM 30, 463 (1989).

10. A. Winkelmann, G. Cios, T. Tokarski, G. Nolze, R. Hielscher, and T. Koziel: EBSD orientation analysis based on experimental Kikuchi reference patterns. Acta Mater. 188, 376 (2020).

11. C. Dong and J.M. Dubois: Quasicrystals and crystalline phases in $\mathrm{Al}_{65} \mathrm{Cu}_{20} \mathrm{Fe}_{10} \mathrm{Cr}_{5}$ alloy. J. Mater. Sci. 26, 1647 (1991).

12. A.P. Tsai, A. Inoue, Y. Yokoyama, and T. Masumoto: Stable icosahedral Al-Pd-Mn and Al-Pd-Re alloys. Mater. Trans. 31, 98 (1990).

13. M. Galano, F. Audebert, I.C. Stone, and B. Cantor: Nanoquasicrystalline Al-Fe-Cr-based alloys. Part I: Phase transformations. Acta Mater. 57, 5107 (2009).

14. W. Wolf, F.G. Coury, M.J. Kaufman, C. Bolfarini, C.S. Kiminami, and W.J. Botta: The formation of quasicrystals in $\mathrm{Al}-\mathrm{Cu}-\mathrm{Fe}-(\mathrm{M}=\mathrm{Cr}, \mathrm{Ni})$ melt-spun ribbons. J. Alloys Compd. 731, 1288 (2018).

15. W. Wolf, B.O. Sitta, L.M. Martini, A.M. Jorge, C. Bolfarini, C.S. Kiminami, and W.J. Botta: Effect of $\mathrm{Cr}$ addition on the formation of the decagonal quasicrystalline phase of a rapidly solidified Al-Ni-Co alloy. J. Alloys Compd. 707, 41 (2017).

16. H. Ma, L. You, and Z. He: Stable quaternary $\mathrm{Al}_{59} \mathrm{Cr}_{23} \mathrm{Fe}_{8} \mathrm{Si}_{10}$ decagonal quasicrystal. Mater. Charact. 166, 110424 (2020).

17. K. Nie, X. Kang, K. Deng, Y. Guo, J. Han, and Z. Zhu: Development of Mg-Zn-Y-Ca alloys containing icosahedral quasicrystal phase through trace addition of Y. J. Mater. Res. 33, 2806 (2018).

18. M. Xu, X. Teng, and J. Geng, Effect of cooling rates on solidification and microstructure of rapidly solidified $\mathrm{Mg}_{57} \mathrm{Zn}_{37} \mathrm{Y}_{6}$ quasicrystal alloy. J. Mater. Res. 30, 3324 (2015).
19. J. Geng, X. Teng, G. Zhou, D. Zhao, and J. Leng: Growth mechanism of an icosahedral quasicrystal and solute partitioning in a Mg-rich Mg-Zn-Y alloy. J. Mater. Res. 29, 942 (2014).

20. J.F. Liu, Z.Q. Yang, and H.Q. Ye: Direct observation of solidstate reversed transformation from crystals to quasicrystals in a Mg alloy. Sci. Rep. 5, 1 (2015).

21. K.F. Kelton, W.J. Kim, and R.M. Stroud: A stable Ti-based quasicrystal. Appl. Phys. Lett. 70, 3230 (1997).

22. Q.G. Han, J.L. Zhong, Q. Zhang, B. Liu, and L.M. Wang: Fabrication and properties of Ti-Zr-Ni quasicrystal and bulk composite materials by high pressure sintering. J. Non. Cryst. Solids 428, 62 (2015).

23. A.P. Tsai, J.Q. Guo, E. Abe, H. Takakura, and T.J. Sato: A stable binary quasicrystal. Nature 408, 537 (2000).

24. F. Labib, N. Fujita, S. Ohhashi, and A.P. Tsai: Icosahedral quasicrystals and their cubic approximants in the Cd-Mg-RE ( $\mathrm{RE}=\mathrm{Y}, \mathrm{Sm}, \mathrm{Gd}, \mathrm{Tb}, \mathrm{Dy}, \mathrm{Ho}, \mathrm{Er}, \mathrm{Tm})$ systems. J. Alloys Compd. 822, $153541(2020)$

25. D. Holland-Moritz, D.M. Herlach, and K. Urban: Observation of the undercoolability of quasicrystal-forming alloys by electromagnetic levitation. Phys. Rev. Lett. 71, 1196 (1993).

26. B.S. Murty, R.V. Koteswara Rao, and N.K. Mukhopadhyay: Stability of quasicrystalline phase in $\mathrm{Al}-\mathrm{Cu}-\mathrm{Fe}, \mathrm{Al}-\mathrm{Cu}-\mathrm{Co}$ and Al-Pd-Mn systems by high energy ball milling. J. Non. Cryst. Solids 334-335, 48 (2004).

27. D. Holland-Moritz, J. Schroers, D.M. Herlach, B. Grushko, and K. Urban: Undercooling and solidification behaviour of melts of the quasicrystal-forming alloys $\mathrm{Al}-\mathrm{Cu}-\mathrm{Fe}$ and $\mathrm{Al}-\mathrm{Cu}-$ Co. Acta Mater. 46, 1601 (1998).

28. B. Grushko, D. Holland-Moritz, and K. Bickmann: Decagonal quasicrystals in Al-Co and ternary alloys containing $\mathrm{Cu}$ and $\mathrm{Ni}$. J. Alloys Compd. 236, 243 (1996).

29. B. Grushko and D. Holland-Moritz: Quasicrystals and related structures in Al-Ni-Co. J. Alloys Compd. 262-263, 350 (1997).

30. B. Grushko and T.Y. Velikanova: Stable and metastable quasicrystals in Al-based alloy systems with transition metals. J. Alloys Compd. 367, 58 (2004).

31. B. Grushko and D. Holland-Moritz: High-Ni Al-Ni-Co decagonal phase. Scr. Mater. 35, 1141 (1996).

32. B. Grushko and T. Velikanova: Formation of quasiperiodic and related periodic intermetallics in alloy systems of aluminum with transition metals. Calphad 31, 217 (2007).

33. W. Wolf, S.A. Kube, S. Sohn, Y. Xie, J.J. Cha, B.E. Scanley, C.S. Kiminami, C. Bolfarini, W.J. Botta, and J. Schroers: Formation and stability of complex metallic phases including quasicrystals explored through combinatorial methods. Sci. Rep. 9, 7136 (2019).

34. F.G. Coury, W.J. Botta, C. Bolfarini, C.S. Kiminami, and M.J. Kaufman: Reassessment of the effects of Ce on quasicrystal 
formation and microstructural evolution in rapidly solidified AlMn alloys. Acta Mater. 98, 221 (2015).

35. F. Audebert, M. Galano, C.T. Rios, H. Kasama, M. Peres, C. Kiminami, W.J. Botta, and C. Bolfarini: Nanoquasicrystalline $\mathrm{Al}-\mathrm{Fe}-\mathrm{Cr}-\mathrm{Nb}$ alloys produced by powder metallurgy. J. Alloys Compd. 577, 650 (2013).

36. K. Stan-Głowińska, L. Lityńska-Dobrzyńska, B. Kania, J. Dutkiewicz, Ł Rogal, W. Skuza, J. Wojewoda-Budka, M.A. Gordillo, and J.M. Wiezorek: Effects of hot-compaction on the structure and properties of Al-Mn-Fe-X alloys strengthened with quasi-crystalline icosahedral phase. Mater. Des. 126, 162 (2017).

37. K. Stan-Głowińska, L. Lityńska-Dobrzyńska, J. Morgiel, A. Góral, M.A. Gordillo, and J.M. Wiezorek: Enhanced thermal stability of a quasicrystalline phase in rapidly solidified Al-Mn-Fe-X alloys. J. Alloys Compd. 702, 216 (2017).

38. J.M. Dubois and E. Belin-Ferré: Friction and solid-solid adhesion on complex metallic alloys. Sci. Technol. Adv. Mater. 15, 034804 (2014).

39. D.A. Rabson: Toward theories of friction and adhesion on quasicrystals. Prog. Surf. Sci. 87, 253 (2012).

40. X. Guo, J. Chen, H. Yu, H. Liao, and C. Coddet: A study on the microstructure and tribological behavior of cold-sprayed metal matrix composites reinforced by particulate quasicrystal. Surf. Coatings Technol. 268, 94 (2015).

41. M. Sales, A. Merstallinger, A.I. Ustinov, S.S. Polishchuk, and T.V. Melnichenko: Effect of the addition of crystalline $\beta$-phase in $\mathrm{Al}-\mathrm{Cu}-\mathrm{Fe}$ quasicrystalline coatings on their tribological properties. Surf. Coatings Technol. 201, 6206 (2007).

42. R.P. Matthews, C.I. Lang, and D. Shechtman: Sliding wear of quasicrystalline coatings. Tribol. Lett. 7, 179 (2000).

43. K. Lee, J. Hsu, D. Naugle, and H. Liang: Multi-phase quasicrystalline alloys for superior wear resistance. Mater. Des. 108, 440 (2016)

44. B.A. Silva Guedes de Lima, R. Medeiros Gomes, S.J. Guedes de Lima, D. Dragoe, M.G. Barthes-Labrousse, R. Kouitat-Njiwa, and J.M. Dubois: Self-lubricating, low-friction, wear-resistant Al-based quasicrystalline coatings. Sci. Technol. Adv. Mater. 17, 71 (2016).

45. J.M. Dubois: So useful, those quasicrystals. Isr. J. Chem. 51, 1168 (2011).

46. W. Wolf, R. Schulz, S. Savoie, C. Bolfarini, C.S. Kiminami, and W.J. Botta: Structural, mechanical and thermal characterization of an Al-Co-Fe-Cr alloy for wear and thermal barrier coating applications. Surf. Coatings Technol. 319, 241 (2017).

47. T. Ferreira, I.L. de Oliveira, G. Zepon, and C. Bolfarini: Rotational outward solidification casting: An innovative single step process to produce a functionally graded aluminum reinforced with quasicrystal approximant phases. Mater. Des. 189, 108544 (2020).
48. D. Caillard, F. Mompiou, L. Bresson, and D. Gratias:

Dislocation climb in icosahedral quasicrystals. Scr. Mater. 49, 11 (2003).

49. Y. Zou, P. Kuczera, A. Sologubenko, T. Sumigawa,

T. Kitamura, W. Steurer, and R. Spolenak: Superior roomtemperature ductility of typically brittle quasicrystals at small sizes. Nat. Commun. 7, 12261 (2016).

50. A.A. Griffith: The phenomena of rupture and flow in solids. Philos. Trans. R. Soc. Lond. A 221, 163 (1921).

51. I. Hutchings and P. Shipway: In Tribology, 2nd ed., I. Hutchings and P. Shipway, eds. (Elsevier, 2017); pp. 107-164.

52. M. Galano, F. Audebert, a.G. Escorial, I.C. Stone, and B. Cantor: Nanoquasicrystalline Al-Fe-Cr-based alloys. Part II. Mechanical properties. Acta Mater. 57, 5120 (2009).

53. A. Inoue: Amorphous, nanoquasicrystalline and nanocrystalline alloys in Al-based systems. Prog. Mater. Sci. 43, 365 (1998).

54. Y. Chen, J. Qiang, and C. Dong: Smearing-type wear behavior of $\mathrm{Al}_{62} \mathrm{Cu}_{25.5} \mathrm{Fe}_{12.5}$ quasicrystal abrasive on soft metals. Intermetallics 68, 23 (2016).

55. D.I. Chukov, A.A. Stepashkin, V.V. Tcherdyntsev, L.K. Olifirov, and S.D. Kaloshkin: Structure and properties of composites based on polyphenylene sulfide reinforced with Al-Cu-Fe quasicrystalline particles. J. Thermoplast. Compos. Mater. 31, 882 (2018).

56. V.V. Tcherdyntsev, A.A. Stepashkin, D.I. Chukov, L.K. Olifirov, and F.S. Senatov: Formation of ethylene-vinyl acetate composites filled with $\mathrm{Al}-\mathrm{Cu}-\mathrm{Fe}$ and $\mathrm{Al}-\mathrm{Cu}-\mathrm{Cr}$ quasicrystalline particles. J. Mater. Res. Technol. 8, 572 (2019).

57. T. Tanabe, S. Kameoka, and A.P. Tsai: Microstructure of leached $\mathrm{Al}-\mathrm{Cu}-\mathrm{Fe}$ quasicrystal with high catalytic performance for steam reforming of methanol. Appl. Catal. A Gen. 384, 241 (2010).

58. F. Zhang, H. Guo, L. Wang, H. Ma, H. Li, L. Zhang, and Z. He: Porous $\mathrm{Al}_{63} \mathrm{Cu}_{25} \mathrm{Fe}_{12}$ quasicrystals covered with $\left(\mathrm{Al}_{11.5} \mathrm{Fe}_{13.9} \mathrm{Cu}_{19.7}\right) \mathrm{O}_{54.9}$ nanosheets. Mater. Charact. 147, 165 (2019).

59. S.K. Pandey, A. Bhatnagar, S.S. Mishra, T.P. Yadav, M.A. Shaz, and O.N. Srivastava: Curious catalytic characteristics of Al-Cu-Fe quasicrystal for de/rehydrogenation of $\mathrm{MgH}_{2}$. J. Phys. Chem. C 121, 24936 (2017).

60. H. Liu, X. Zhai, Z. Li, X. Tao, W. Liu, J. Zhao, D. Jiang, and S. Gao: Preparation and electrochemical hydrogen storage properties of MWCNTs-doped $\mathrm{Ti}_{49} \mathrm{Zr}_{26} \mathrm{Ni}_{25}$ alloy containing quasicrystal phase. Solid State Sci. 83, 17 (2018).

61. H. Liu, W. Liu, Y. Sun, P. Chen, J. Zhao, X. Guo, and Z. Su: Preparation and electrochemical hydrogen storage properties of $\mathrm{Ti}_{49} \mathrm{Zr}_{26} \mathrm{Ni}_{25}$ alloy covered with porous polyaniline. Int. J. Hydrog. Energy 45, 11675 (2020).

62. K.F. Kelton and P.C. Gibbons: Hydrogen storage in quasicrystals. MRS Bull. 22, 69 (1997). 
63. V.S. Shekhtman, H.G. Hakobyan, A.G. Aleksanyan, S.K. Dolukhanyan, O.P. Ter-Galstyan, and M.K. Sakharov: The formation of quasicrystals and their hydrides in Ti-Zr-Ni system. Int. J. Hydrog. Energy 36, 1206 (2011).

64. J. Dubois: New prospects from potential applications of quasicrystalline materials. Mater. Sci. Eng. A 294-296, 4 (2000).

65. P. Barua, B.S. Murty, B.K. Mathur, and V. Srinivas: Nanostructured icosahedral phase formation in $\mathrm{Al}_{70} \mathrm{Cu}_{20} \mathrm{Fe}_{10}$ by mechanical alloying: Comprehensive study. J. Appl. Phys. 91, 5353 (2002).

66. T.A. Sviridova, A.P. Shevchukov, E.V. Shelekhov, D.L. Diakonov, V.V. Tcherdyntsev, and S.D. Kaloshkin: The quasicrystalline phase formation in $\mathrm{Al}-\mathrm{Cu}-\mathrm{Cr}$ alloys produced by mechanical alloying. J. Alloys Compd. 509, S299 (2011).

67. E. Huttunen-Saarivirta, and J. Vuorinen: Preparation and characterisation of melt-spun Al-Cu-Fe quasicrystals. Intermetallics 13, 885 (2005).

68. W. Wolf, C. Bolfarini, C.S. Kiminami, and W.J. Botta: Designing new quasicrystalline compositions in Al-based alloys. J. Alloys Compd. 823, 153765 (2020).

69. D.S. Shaitura and A.A. Enaleeva: Fabrication of quasicrystalline coatings: A review. Crystallogr. Rep. 52, 945 (2007).

70. W. Wolf, L.C.R. Aliaga, D.N. Travessa, C.R.M. Afonso, C. Bolfarini, C.S. Kiminami, and W.J. Botta: Enhancement of mechanical properties of aluminum and 2124 aluminum alloy by the addition of quasicrystalline phases. Mater. Res. 19, 74 (2016).

71. W. Wolf, L.P.M. e Silva, G. Zepon, C.S. Kiminami,

C. Bolfarini, and W.J. Botta: Single step fabrication by spray forming of large volume Al-based composites reinforced with quasicrystals. Scr. Mater. 181, 86 (2020).

72. W. Wolf, C. Bolfarini, C.S. Kiminami, and W.J. Botta: Fabrication of Al-matrix composite reinforced with quasicrystals using conventional metallurgical fabrication methods. Scr. Mater. 173, 21 (2019).

73. Y. Fu, N. Kang, H. Liao, Y. Gao, and C. Coddet: An investigation on selective laser melting of $\mathrm{Al}-\mathrm{Cu}-\mathrm{Fe}-\mathrm{Cr}$ quasicrystal: From single layer to multilayers. Intermetallics 86, 51 (2017).

74. G.Y. Koga, A.M.B. e Silva, W. Wolf, C.S. Kiminami, C. Bolfarini, and W.J. Botta: Microstructure and mechanical behavior of $\mathrm{Al}_{92} \mathrm{Fe}_{3} \mathrm{Cr}_{2} \mathrm{X}_{3}(\mathrm{X}=\mathrm{Ce}, \mathrm{Mn}, \mathrm{Ti}$, and $\mathrm{V})$ alloys processed by centrifugal force casting. J. Mater. Res. Technol. 8, 2092 (2019).

75. H.R. Leonard, S. Rommel, T.J. Watson, T. Policandriotes, and M. Aindow: Development of quasicrystal morphology in gas-atomized icosahedral-phase-strengthened aluminum alloy powders. Mater. Des. 182, 108094 (2019).

76. T.J. Watson, A. Nardi, A.T. Ernst, I. Cernatescu, B.A. Bedard, and M. Aindow: Cold spray deposition of an icosahedral-phase-strengthened aluminum alloy coating. Surf. Coatings Technol. 324, 57 (2017).
77. N. Kang, Y. Fu, P. Coddet, B. Guelorget, H. Liao, and

C. Coddet: On the microstructure, hardness and wear behavior of $\mathrm{Al}-\mathrm{Fe}-\mathrm{Cr}$ quasicrystal reinforced $\mathrm{Al}$ matrix composite prepared by selective laser melting. Mater. Des. 132, 105 (2017).

78. A. Inoue, M. Watanabe, H.M. Kimura, F. Takahashi, A. Nagata, and T. Masumoto: High mechanical strength of quasicrystalline phase surrounded by fcc- $\mathrm{Al}$ phase in rapidly solidified Al-Mn-Ce alloys. Mater. Trans. JIM 33, 723 (1992).

79. A. Inoue and H. Kimura: High-strength aluminum alloys containing nanoquasicrystalline particles. Mater. Sci. Eng. A 286, 1 (2000).

80. F. Schurack, J. Eckert, and L. Schultz: High strength Al-alloys with nanoquasicrystalline phase as main component. Nanostruct. Mater. 12, 107 (1999).

81. F. Schurack, J. Eckert, and L. Schultz: Quasicrystalline Al-alloys with high strength and good ductility. Mater. Sci. Eng. A 294296, 164 (2000).

82. F. Schurack, J. Eckert, and L. Schultz: Synthesis and mechanical properties of cast quasicrystal-reinforced Al-alloys. Acta Mater. 49, 1351 (2001).

83. M. Galano, F. Audebert, A.G. Escorial, I.C. Stone, and B. Cantor: Nanoquasicrystalline Al-Fe-Cr-based alloys with high strength at elevated temperature. J. Alloys Compd. 495, 372 (2010).

84. F. Audebert, M. Galano, and F. Saporiti: The use of $\mathrm{Nb}$ in rapid solidified Al alloys and composites. J. Alloys Compd. 615, S621 (2015).

85. M. Galano, A. Marsh, F. Audebert, W. Xu, and M. Ramundo: Nanoquasicrystalline Al-based matrix $/ \gamma-\mathrm{Al}_{2} \mathrm{O}_{3}$ nanocomposites. J. Alloys Compd. 643, S99 (2015).

86. K. Stan-Głowińska, L. Lityńska-Dobrzyńska, and Ł. Rogal: Influence of $\mathrm{Fe}$ addition on the formation of a quasicrystalline phase in bulk Al-rich Al Mn base alloys. Mater. Charact. 128, 203 (2017).

87. K. Stan-Głowińska, Ł. Rogal, A. Góral, A. Wierzbicka-Miernik, J. Wojewoda-Budka, N. Schell, and L. Lityńska-Dobrzyńska. J. Mater. Sci. 52, 7794 (2017).

88. I. Naglič, Z. Samardžija, K. Delijić, S. Kobe, J-M. Dubois, B. Leskovar, and B. Markoli: Metastable quasicrystals in Al-Mn alloys containing copper, magnesium and silicon. J. Mater. Sci. 52, 13657 (2017).

89. I. Naglič, Z. Samardžija, K. Delijić, S. Kobe, B. Leskovar, and B. Markoli: Synthesis of an Al-Mn-Based Alloy Containing In Situ-Formed Quasicrystals and Evaluation of Its Mechanical and Corrosion Properties. JOM 70, 2698 (2018).

90. I. Todd, Z. Chlup, J.G. O’Dwyer, M. Lieblich, and

A. García-Escorial: The influence of processing variables on the structure and mechanical properties of nano-quasicrystalline reinforced aluminium alloys. Mater. Sci. Eng. A 375-377, 1235 (2004). 
91. S. Pedrazzini, M. Galano, F. Audebert, D.M. Collins,

F. Hofmann, B. Abbey, A.M. Korsunsky, M. Lieblich, A. Garcia Escorial, and G.D.W. Smith: Strengthening mechanisms in an Al-Fe-Cr-Ti nano-quasicrystalline alloy and composites. Mater. Sci. Eng. A 672, 175 (2016).

92. T.J. Watson, M.A. Gordillo, I. Cernatescu, and M. Aindow: Structure and mechanical properties in a powder-processed icosahedral-phase-strengthened aluminum alloy. Scr. Mater. 123 , 51 (2016).

93. H.R. Leonard, S. Rommel, M.X. Li, T.J. Watson,

T. Policandriotes, and M. Aindow: Microstructure/mechanical behavior relationships in upset-forged powder-processed $\mathrm{Al}$ alloys containing icosahedral quasicrystalline dispersoids. Mater. Sci. Eng. A 788, 139487 (2020).

94. S. Rommel, H.R. Leonard, T.J. Watson, T. Policandriotes, and M. Aindow: Corrosion phenomena in a powder-processed $\mathrm{Al}$ alloy containing icosahedral quasicrystalline dispersoids. Corros. Sci.,177, 108970 (2020).

95. N. Kang, M. El Mansori, J.L. Lu, X. Lin, and W.D. Huang: Effect of selective post-aging treatment on subsurface damage of quasicrystal reinforced $\mathrm{Al}$ composite manufactured by selective laser melting. Wear 426-427, 934 (2019).

96. S.K. Kairy, O. Gharbi, J. Nicklaus, D. Jiang, C.R. Hutchinson, and N. Birbilis: On the characterization of a hitherto unreported icosahedral quasicrystal phase in additively manufactured aluminum alloy AA7075. Metall. Mater. Trans. A Phys. Metall. Mater. Sci. 50, 529 (2019).

97. M. Quiquandon, A. Quivy, J. Devaud, F. Faudot, S. Lefebvre, M. Bessière, and Y. Calvayrac: Quasicrystal and approximant structures in the Al-Cu-Fe system. J. Phys. Condens. Matter 8, 2487 (1996).

98. A.P. Tsai, K. Aoki, A. Inoue, and T. Masumoto: Synthesis of stable quasicrystalline particle-dispersed Al base composite alloys. J. Mater. Res. 8, 5 (1993).

99. F. Tang, I.E. Anderson, T. Gnaupel-Herold, and H. Prask: Pure Al matrix composites produced by vacuum hot pressing: Tensile properties and strengthening mechanisms. Mater. Sci. Eng. A 383, 362 (2004).

100. S.D. Kaloshkin, V.V. Tcherdyntsev, A.I. Laptev, and

H. Physics: Structure and mechanical properties of mechanically alloyed Al/Al-Cu-Fe composites. J. Mater. Sci. 9, 5399 (2004).

101. F. Ali, S. Scudino, M.S. Anwar, R.N. Shahid, V.C. Srivastava, V. Uhlenwinkel, M. Stoica, G. Vaughan, and J. Eckert: Al-based metal matrix composites reinforced with $\mathrm{Al}-\mathrm{Cu}-\mathrm{Fe}$ quasicrystalline particles: Strengthening by interfacial reaction. J. Alloys Compd. 607, 274 (2014).

102. J. Bonneville, G. Laplanche, A. Joulain, V. Gauthier-Brunet, and S. Dubois: Al-matrix composite materials reinforced by Al-Cu-Fe particles. J. Phys. Conf. Ser. 240, 5 (2010).
103. L. Lityńska-Dobrzyńska, J. Dutkiewicz, K. Stan-Głowińska, W. Wajda, L. Dembinski, C. Langlade, and C. Coddet: Characterization of aluminium matrix composites reinforced by Al-Cu-Fe quasicrystalline particles. J. Alloys Compd. 643, S114 (2015).

104. Y. Shadangi, S. Sharma, V. Shivam, J. Basu, K. Chattopadhyay, B. Majumdar, and N.K. Mukhopadhyay: Fabrication of Al-CuFe quasicrystal reinforced 6082 aluminium matrix nanocomposites through mechanical milling and spark plasma sintering. J. Alloys Compd. 828, 154258 (2020).

105. G. Laplanche, A. Joulain, J. Bonneville, V. Gauthier-Brunet, S. Dubois, and T. El Kabir: Microstructural and mechanical study of an $\mathrm{Al}$ matrix composite reinforced by $\mathrm{Al}-\mathrm{Cu}-\mathrm{Fe}$ icosahedral particles. J. Mater. Res. 25, 957 (2010).

106. A. Joseph, V. Gauthier-Brunet, J.P. Monchoux, A. Joulain, F. Brisset, C. Tromas, J. Douin, F. Pettinari, J. Bonneville, and S. Dubois: Formation processes of the $\omega-\mathrm{Al}_{70} \mathrm{Cu}_{20} \mathrm{Fe}_{10}$ phase synthesized by SPS technique. J. Alloys Compd. 699, 1157 (2017).

107. T. El Kabir, A. Joulain, V. Gauthier, S. Dubois, J. Bonneville, and D. Bertheau: Hot isostatic pressing synthesis and mechanical properties of Al/Al-Cu-Fe composite materials. J. Mater. Res. 23, 904 (2008).

108. G. Laplanche, A. Joulain, J. Bonneville, R. Schaller, and T. El Kabir: Microstructures and mechanical properties of Al-base composite materials reinforced by $\mathrm{Al}-\mathrm{Cu}-\mathrm{Fe}$ particles. J. Alloys Compd. 493, 453 (2010).

109. F. Ali, S. Scudino, G. Liu, V.C. Srivastava, N.K. Mukhopadhyay, M. Samadi Khoshkhoo, K.G. Prashanth, V. Uhlenwinkel,

M. Calin, and J. Eckert: Modeling the strengthening effect of $\mathrm{Al}-$ $\mathrm{Cu}-\mathrm{Fe}$ quasicrystalline particles in Al-based metal matrix composites. J. Alloys Compd. 536, S130 (2012).

110. E. Fleury, S.M. Lee, G. Choi, W.T. Kim, and D.H. Kim: Comparison of $\mathrm{Al}-\mathrm{Cu}-\mathrm{Fe}$ quasicrystalline particle reinforced $\mathrm{Al}$ composites fabricated by conventional casting and extrusion. J. Mater. Sci. 36, 963 (2001).

111. Y. Yuan, H. Hou, Y. Zhao, and F. Yan: Characterization of aluminium matrix composites reinforced by $\mathrm{Al}-\mathrm{Cu}-\mathrm{Fe}-\mathrm{Cr}$ quasicrystalline particles. Mater. Res. Express 6, 076544 (2019).

112. F.Z. Li, L.H. Tian, R.T. Li, Y. Wang, and Z.Q. Liu: Microstructure and wear resistance properties of $\mathrm{Al} / \mathrm{Al}-\mathrm{Cu}-\mathrm{Cr}-$ Fe composites consolidated using spark plasma sintering. Compos. Interfaces 27, 6440 (2019).

113. R.T. Li, Z.Y. Wang, W. Sun, H.L. Hu, K.A. Khor, Y. Wang, and Z.L. Dong: Microstructure and strengthening mechanisms in the $\mathrm{Al} / \mathrm{Al}-\mathrm{Cu}-\mathrm{Cr}-\mathrm{Fe}$ composites consolidated using spark plasma sintering. Mater. Charact. 157, 109917 (2019).

114. D. Lu, J.P. Celis, S. Kenzari, V. Fournée, and D.B. Zhou: Tribological behavior of aluminum matrix composites containing complex metallic alloys $\mathrm{AlCuFeB}$ or $\mathrm{AlCuFeCr}$ particles. Wear 270, 528 (2011). 
115. W. Wolf, G.Y. Koga, R. Schulz, S. Savoie, C.S. Kiminami,

C. Bolfarini, and W.J. Botta: Wear and corrosion performance of Al-Cu-Fe-(Cr) quasicrystalline coatings produced by HVOF.

J. Therm. Spray Technol. 29, 1195 (2020).
116. C.I. Lang, D.J. Sordelet, M.F. Besser, D. Schechtman,

F.S. Biancaniello, and E.J. Gonzalez: Quasicrystalline coatings: Thermal evolution of structure and properties. J. Mater. Res. 15, 1894 (2000). 